\title{
Identification of subfunctionalized aggregate-remodeling J-domain proteins in plants
}

Yogesh Tak ${ }^{1}$, Silviya S. Lal ${ }^{1}$, Shilpa Gopan ${ }^{1,3}$, Madhumitha Balakrishnan ${ }^{1}$, Amit K. Verma ${ }^{1,4}$, Sierra J. Cole ${ }^{2}$, Rebecca E. Brown ${ }^{2,5}$, Rachel E. Hayward ${ }^{2}$, Justin K. Hines ${ }^{2}$, Chandan Sahi ${ }^{1, *}$

${ }^{1}$ Department of Biological Sciences, Indian Institute of Science Education and Research Bhopal, India

${ }^{2}$ Department of Chemistry, Lafayette College, Pennsylvania, USA

${ }^{3}$ Present Address: Indian Institute of Science Education and Research, Pune, India

${ }^{4}$ Present Address: Department of Biochemistry, University of Wisconsin-Madison, Wisconsin, USA

${ }^{5}$ Present Address: Department of Biology and Program in Genetics, Tufts University, Massachusetts, USA

"Corresponding author: Chandan Sahi

E-mail: sahi@iiserb.ac.in

Running title: Aggregate remodeling J-domain proteins of $A$. thaliana

Keywords: J-domain protein (JDP), J-protein, Hsp40, Hsp70, Hsp100, aggregate remodeling, prion, amyloid, stress 


\begin{abstract}
Hsp70s and J-domain proteins (JDPs) are among the most critical components of the cellular protein quality control machinery, playing crucial roles in preventing and solubilizing cytotoxic protein aggregates. Bacteria, yeast and plants additionally have large, multimeric Hsp 100-class disaggregases which, allow the resolubilization of otherwise "dead-end" aggregates, including amyloids. JDPs interact with aggregated proteins and specify the aggregate remodeling activities of Hsp70s and Hsp100s. Plants have a complex network of cytosolic Hsp70s and JDPs, however the aggregate remodeling properties of plant JDPs are not well understood. Here we identify evolutionary-conserved Class II JDPs in the model plant Arabidopsis thaliana with distinct aggregate remodeling functionalities. We identify eight plant orthologs of the yeast protein, Sis1, the principal JDP responsible for directing the yeast chaperone machinery for remodeling protein aggregates. Expression patterns vary dramatically among the eight paralogous proteins under a variety of stress conditions, indicating their subfunctionalization to address distinct stressors. Consistent with a role in solubilizing cytotoxic protein aggregates, six of these plant JDPs associate with heat-induced protein aggregates in vivo as well as colocalize with plant Hsp101 to distinct heat-induced protein aggregate centers. Finally, we show that these six JDPs can differentially remodel multiple model protein aggregates in yeast confirming their involvement in aggregate resolubilization. These results demonstrate that compared to complex metazoans, plants have a robust network of JDPs involved in aggregate remodeling activities with the capacity to process a variety of protein aggregate conformers.
\end{abstract}

\title{
Introduction
}

All organisms face the challenge of maintaining cellular proteostasis for proper growth and development in the context of constant and diverse stressors. Proteostasis ensures the balance between numerous cellular processes, including protein synthesis, folding, transport, aggregation, and turnover, thereby maintaining the overall fidelity of cellular proteome (1). Proteins can misfold for a plethora of reasons, including cellular stresses, mutations, defects in protein synthesis or sorting, or chaperone overload (2). Misfolded proteins can form abnormal contacts with other proteins and seed the formation of larger protein aggregates, which are often cytotoxic (3). Broadly, these aggregates are either amorphous deposits or ordered amyloid fibrils $(4,5)$. Either of these aggregates can further disrupt cellular proteostasis, which can hamper vital cellular processes (6).

Being sessile, plants have an increased burden to continuously integrate their cellular physiology with diverse environmental cues to maintain proper growth and development as well as safeguard reproductive success. Protein homeostasis in plants is vulnerable to adverse biotic or abiotic stress conditions that are detrimental to plant health and can ultimately lead to a decrease in productivity (7). High-temperature stress is among the primary factors causing proteotoxic stress, eventually leading to adverse physiological consequences in plants $(8,9)$. To counter stress-induced challenges, plants are equipped with a vast network of heat-shock proteins (Hsps), often referred to as molecular chaperones (10). Molecular chaperones assist in protein folding, prevention of misfolding and aggregation, reactivation of aggregates, and degradation or sequestration of problematic protein substrates $(5,11$, 12).

Small heat shock proteins (sHsps), Hsp40s, Hsp70s, and Hsp100s (when present) play vital roles in liberating and refolding trapped polypeptides from protein aggregates (5). sHsps work as the first line of defense against proteotoxic stress, as they bind to misfolded proteins in an ATP-independent fashion and prevent irreversible aggregation (13). Moreover, denatured protein substrates bound to sHsps remain in a folding competent state so that Hsp70s, with their obligate cochaperone Hsp40s (alternatively and hereafter called J-domain proteins or JDPs) can reactivate them (14). Additionally, in bacteria, yeast and plants the Hsp70: JDP system further cooperates with AAA+ ATPases of the Caseinolytic Protease B/heat shock protein 100 (ClpB/Hsp100) family in a synergic, ATP-driven, bichaperone system for disaggregation, in which the JDP acts as a cochaperone and deliver substrates to Hsp70 and therefore Hsp100 (15-17). The disaggregation activities of Hsp100s have been conserved with similar proteins found in bacteria (ClpB), yeast (Hsp104), and plants (Hsp101) (18-20). sHsps, JDPs, Hsp70s, and Hsp101 have been shown to have a significant role in stress sensing and tolerance 
(21-26). Studies have implicated sHsps and Hsp101 in aggregate remodeling in plants $(21,27)$, however there is no such report on plant JDPs.

JDPs are crucial co-chaperones that define the substrate specificities of Hsp70 and Hsp100 (17, 28,29 ). JDPs are a highly heterogeneous group of proteins. All JDPs have a conserved J-domain, which is critical for the stimulation of the otherwise weak ATPase activity of their partner Hsp70s (15). Based on their domain organization and similarity to DnaJ of E. coli, JDPs have been divided into three classes, Class I, II and III (30). Among these, the Class II JDPs, including Sis1 in yeast, DNAJB1 in mammals and DROJ1 in flies have been implicated in aggregate remodelling (31-33). The aggregate remodelling activities of Sis1 are best understood. Sis1 is an essential cytosolic Class II JDP that contains a Jdomain, a glycine-rich central region (G/F-G/M), a carboxyl-terminal region (CTD), which has a client binding pocket, and dimerization domain (DD) (34). Sis1 is required for the remodeling of different protein aggregates including terminally misfolded proteins and prion $(31,35-38)$. Prions are selfreplicating proteinaceous infectious particles. One characteristic feature of all prions is that they have the ability to convert the cellular pool of the prion protein into a misfolded form, resulting into aggregation (39). Among all 22 JDPs in yeast, Sis1 uniquely cooperates with Hsp70 and Hsp104 in fragmenting prion aggregates such as $\left[\mathrm{PSI}^{+}\right]$and $\left[R N Q^{+}\right]$to generate seeds, an essential step in the maintenance of prions in yeast cells $(17,31,40)$. The $\left[P S I^{+}\right]$prion is formed of the Sup35 protein, a translation termination factor. In $\left[\mathrm{PSI}^{\dagger}\right]$ cells, Sup35 is sequestered in amyloid aggregates, leading to the nonsense-suppression phenotype. The $\left[\mathrm{PSI}^{+}\right]$prion has different heritable states which result from amyloid polymorphisms (alternative conformers) (41). These are termed "prion strains" in mammalian systems or "variants" in yeast. $\left[\mathrm{PSI}^{+}\right]$variants are classified as "weak" and "strong" based on the strength of the nonsense suppression phenotype, which results from differences in the soluble pool of Sup35. Variants with distinct aggregate sizes and number of prion seeds per cell lead to differential amounts of unincorporated Sup35 which alters translational read through efficiencies (42). In yeast strains with a nonsense mutation in the adenosine synthesis pathway, [psi $\left.i^{-}\right]$strains form red colonies due to the accumulation of a red-pigmented intermediate. Cells bearing strong $\left[\mathrm{PSI}^{+}\right]$variants, in contrast, grow into white or light pink colonies, while cells with weak $\left[\mathrm{PSI}^{+}\right]$variants form dark pink colonies due to translational readthrough and partial adenosine synthesis. Apart from $\left[\mathrm{PSI}^{+}\right]$ maintenance, Sis1 is the only factor other than Hsp70 and Hsp104 that is known to be required for the maintenance of the yeast prion $\left[R N Q^{+}\right](35,38)$. Previous reports suggest that the human $(\operatorname{Hdj} 1)$, and Drosophila (Droj1) ortholog of Sis1 can maintain $\left[R N Q^{+}\right]$and strong $\left[\mathrm{PSI}^{+}\right]$prions in budding yeast $(31,32,43)$.

To identify and functionally characterize aggregate remodeling JDPs in plants, we chose the orthologs of Sis1 in the model plant Arabidopsis thaliana. Previously we showed that the A. thaliana Class II JDP, atDjB1 could substitute for Sis lin budding yeast (44). Besides rescuing the lethality of sis $1 \Delta$ strain, atDjB1 could also maintain the commonly-studied yeast prions, $\left[R N Q^{+}\right]$and $\left[P S I^{+}\right]$. Interestingly, Arabidopsis has at least seven more Sis1-like JDPs (atDjBs). However, the aggregate remodeling properties of these JDPs have not been characterized. Here we show that atDjBs can associate with heat-induced protein aggregates and co-localize with Hsp101 disaggregase, the marker for heat-denatured protein aggregates in isolated protoplasts. In the absence of an assayable loss of function phenotype in Arabidopsis and lack of model protein aggregate substrates in plants we characterized the functional specificities and aggregate-remodeling properties of six of these plant JDPs using yeast genetic tools. Selected, well characterized yeast prions were exploited as model protein aggregates, as these have been immensely useful in understanding the aggregate remodeling functions of chaperones including JDPs $(45,46)$. The six tested atDjBs not only complement essential functions of Sis1 but also differentially remodel yeast prions. Put together, our results indicate that plants have an elaborate network of aggregate remodeling chaperones. Moreover, the aggregate remodeling properties of JDPs seem to be subfunctionalized to provide better adaptation to land plants during diverse environmental conditions. 


\section{Results}

\section{atDjBs are highly similar to Sis1}

We previously found eight orthologs of Sis1 in A. thaliana, namely, atDjB1, atDjB2, atDjB3, atDjB4, atDjB5, atDjB6, atDjB10, and atDjB17 (44). These atDjBs not only share the domain organization of Sis1 but also exhibit high sequence similarity among one another $(68.1 \%-89.4 \%)$, with Sis1 (49.20\%-53.9\%), and with the human ortholog, Hdj1 (57.5\%-63.7\%). (Fig. 1A; 1B; S1; Table 1). The e-values range between $1.00 \mathrm{E}-61$ (atDjB1) to $2.00 \mathrm{E}-52$ (atDjB17) obtained by NCBI BLASTp analyses using $S$. cerevisiae Sis1 as a query sequence (Fig. S2A). Further, the C-terminal domains of all atDjBs protein share high degree of similarity to Sis1 (Fig.S2B). Notably, even the hydrophobic client binding pocket is highly conserved among all eight JDPs (Fig. S2C).

\section{atDjBs are expressed differentially}

To understand the functional significance of these atDjBs in A. thaliana, we first analyzed their expression under different abiotic stress conditions through quantitative RT-PCR (Fig. 1C) (44). Interestingly, only atDjB2 and atDjB3 were significantly upregulated under heat stress $\left(37^{\circ} \mathrm{C}\right.$ for 60 min), atDjB3, atDjB4, atDjB10, and atDjB17 were induced by salt stress $(150 \mathrm{mM} \mathrm{NaCl}$ for $24 \mathrm{~h})$, while atDjB5, atDjB6, and atDjB10 were cold stress $\left(4^{\circ} \mathrm{C}\right.$ for $\left.24 \mathrm{~h}\right)$ regulated. Similarly, atDjB1 and atDjB4 showed significant down-regulation under heat, cold, and salt stress, and atDjB6 only under salt stress. Our results show that the atDjBs are expressed differentially and even though highly similar, these proteins might have different stress associated functionalities in A. thaliana.

\section{atDjBs interact with misfolded or aggregated proteins}

Under high temperature stress, a large portion of the plant proteome faces the risk of misfolding and aggregation (47). To test whether atDjBs are involved in heat stress response, we looked at the at $\mathrm{DjB} 1$ protein levels in total protein fraction of unstressed, acclimatized, and heat-stressed samples. A band corresponding to atDjB1 was detected in unstressed $\left(23^{\circ} \mathrm{C}\right)$ conditions, which was upregulated upon acclimatization $\left(38^{\circ} \mathrm{C}\right.$ for $90 \mathrm{~min}$, followed by $120 \mathrm{~min}$ at $\left.23^{\circ} \mathrm{C}\right)$ and under heat stress $(180 \mathrm{~min}$ at $45^{\circ} \mathrm{C}$ with preconditioning) (Fig.2). However, the polyclonal antibody used in this assay was raised against atDjB1-CTD and cross-reacts with atDjB2, atDjB3, and atDjB4 (Fig. S3), so at this time we cannot rule out the possibility that the band visible on the western blots represents the heat-inducible orthologs, atDjB2 and atDjB3 or other atDjBs as well.

Since some JDPs are known to prevent irreversible aggregation of heat-denatured proteins by interacting with them, we asked if atDjBs have a similar role in remodeling heat-denatured proteins in A. thaliana. To test this, we first sought to identify the association of atDjBs with the heat-denatured proteins in planta. We assessed the presence of atDjBs in either soluble or pellet fractions under control conditions or after acclimatization and heat stress. During heat stress, atDjB(s) partitioned into the insoluble fraction similar to the sHSP C1, a known marker for heat-induced protein aggregates (Fig. 2). As expected, GAPDH was detected only in the soluble fractions of all samples, which perfectly aligns with a previous report (21). This result suggests that atDjBs interact with the heat-denatured protein aggregates in cells.

\section{atDjBs colocalize with Hsp101 to distinct heat-induced punctae in $A$. thaliana protoplasts}

To individually test the ability of atDjBs to associate with heat-denatured protein aggregates, we generated C-terminal GFP-tagged constructs of atDjB1-6. Even after repeated efforts, we could not clone the full-length cDNAs of atDjB10 and atDjB17, so these were not included in any further studies. atDjB1-6-GFP fusion proteins were transiently expressed in A. thaliana protoplasts, and their subcellular localization was assessed using confocal laser scanning microscopy at $23^{\circ} \mathrm{C}$, or after heat stress for either $30 \mathrm{~min}$ at $38^{\circ} \mathrm{C}$ or $15 \mathrm{~min}$ at $45^{\circ} \mathrm{C}$. Under control conditions, atDjB1-6 exhibited a diffuse fluorescence pattern (Fig. 3). In contrast, heat stress resulted in a transition from diffuse to punctate cellular distribution (Fig. S4A; S4B).

Hsp101 is the major disaggregase of the Hsp100 class in A. thaliana that is known to solubilize heat-induced aggregates and improve thermotolerance (21). Upon heat stress, Hsp101 forms multiple cytosolic puncta and, thus, has been used as a marker for protein aggregate centers (PACs)in plant cells $(27,48)$. Hsp104, the yeast ortholog of Arabidopsis Hsp101, works with the Hsp70: JDP chaperone 
machinery to remodel multiple types of aggregates $(17,49)$. Previously, we showed that atDjB1 could remodel yeast model aggregate proteins in place of Sis1, demonstrating its ability to cooperate with yeast $\mathrm{Hsp} 70$ in aggregate remodeling (44). Because atDjBs fractionated with heat-denatured aggregates in our centrifugation assays, we hypothesized that at $\mathrm{DjBs}$ studied here likely to have a role in aggregate remodeling in plants, and if so, they should colocalize with Hsp101 at PACs during heat stress. To test this, we generated an N-terminal RFP-tagged Hsp101 construct and co-transformed A. thaliana protoplasts with plasmids expressing individual atDjB-GFP constructs. We focused only on heat stress treatment at $38^{\circ} \mathrm{C}$ for $30 \mathrm{~min}$ to check the behavior of the proteins, as $15 \mathrm{~min}$ at $45^{\circ} \mathrm{C}$ resulted in several poly-disperse punctae that were not easily differentiable from each other (Fig. S5B). Similarly, during the control $\left(23^{\circ} \mathrm{C}\right)$ condition, fluorescence was not differentiable as all proteins analyzed displayed a diffuse cytosolic distribution in protoplasts (Fig. S5A). As shown by the merged confocal fluorescence images and statistical analysis, atDjB1-4 and atDjB6 colocalized with Hsp101 at distinct punctate structures in Arabidopsis protoplasts following heat stress at $38^{\circ} \mathrm{C}$ for $30 \mathrm{~min}$ (Fig. 4A). Unlike other atDjBs, atDjB5 didn't show significant co-localization with Hsp101-RFP, although it also accumulated at distinct punctate structures (Fig. 4B). These results suggest that, upon high-temperature, atDjBs are distributed to distinct heat-induced aggregates along with Hsp101 at PACs, indicating that they likely work with Hsp101 to remodel and/or solubilize heat-denatured protein aggregates in A. thaliana.

\section{atDjB1- 6 can substitute for Sis1 in budding yeast}

To further explore the functional similarity and diversity among the six atDjB paralogs, we took advantage of the unicellular eukaryote Saccharomyces cerevisiae, in which, as noted above, the role of Sis1 in protein aggregate remodeling is well characterized. We first tested if atDjB1-6 rescue the viability of a sis $1 \triangle$ strain. For this, full-length cDNAs of atDjB1-6 were cloned in vectors with a constitutive TEF1 promoter (50). A sis $1 \triangle$ yeast strain harboringSIS1 from a URA3 plasmid (URA3$S I S 1)$ was transformed with plasmids expressing individual atDjB1-6 proteins. Transformants were grown on medium containing 5-FOA to counterselect against the URA3-SIS1 plasmid, and thus maintain only the plasmid expressing individual atDjB proteins. Results showed that like atDjB1, other five atDjBs could also substitute for Sis1 in yeast (Fig. 5A). Importantly, this result also implies that all six plant proteins can regulate the ATPase activity of yeast Hsp70s. Next, we assessed the growth of sis $1 \Delta$ cells expressing different atDjBs at different temperatures. As shown in (Fig. 5B), atDjB1-4 rescued growth of sis $1 \Delta$ cells similarly to Sis 1 . However, atDjB5 and atDjB6 could not support growth at $34^{\circ} \mathrm{C}$ (Fig. 5B). This partial complementation by atDjB5 and atDjB6 was most likely due to functional differences rather than protein expression, as evidenced by comparable expression levels of all the tested 1X-HA tagged atDjB proteins (Fig. 5C).

\section{atDjBs can maintain strong $\left[P S I^{+}\right]$universally and weak $\left[P S I^{+}\right]$differentially}

As atDjBs could perform the essential functions of Sis1, we next asked if these proteins could also remodel different protein aggregates. Since very little is known about aggregate prone proteins in plants and robust aggregate remodeling assays are yet to be standardized for plant JDPs, we choose yeast prions as model protein aggregates as they have been extensively used to understand the role of molecular chaperones, especially JDPs and Hsp104 in aggregate remodeling and solubilization (45, 51). We utilized four different well studied variants of the $\left[P S I^{+}\right]$prion in yeast: the strong $\left[P S I^{+}\right]^{\mathrm{Sc} 4}$ and $\left[P S I^{+}\right]^{\mathrm{VH}}$ and the weak $\left[P S I^{+}\right]^{\mathrm{Sc} 37}$ and $\left[P S I^{+}\right]^{\mathrm{VL}}$ variants $(52,53)$. Prion-bearing sis $1 \Delta$ strains expressing URA3-SIS1 were transformed with CEN-TEF plasmids expressing individual atDjB1-6 proteins. 5FOA was again used to counterselect against the URA3-SISI plasmid, and then strains expressing individual atDjB proteins were analyzed for prion maintenance. All six atDjBs were able to support strong variants of $\left[\mathrm{PSI}^{+}\right]$, as confirmed by colony color assay (Fig. 6A). However, only atDjB2 and atDjB3 were able to maintain the weak $\left[P S I^{+}\right]$variant $\left[P S I^{+}\right]^{\text {Sc37 }}$, whereas no plant ortholog maintained $\left[P S I^{+}\right]^{\mathrm{VL}}$. To confirm if colony color accurately reflects the aggregate status of the prion, particularly for the $\left[\mathrm{PSI}^{+}\right]^{\mathrm{Sc} 37}$ strains, semi-denaturing detergent agarose gel electrophoresis (SDDAGE), a biochemical assay for resolving and visualizing detergent-resistant protein aggregates was used. Indeed, large detergent-resistant Sup35 aggregates of variable sizes, indicative of prion amyloid aggregates, were observed only in cells expressing atDjB2 and atDjB3, confirming the colony color results (Fig. 6B). The genetic background of a yeast strain sometimes impacts results of yeast prion assays (54). To rule out an impact of a particular genetic polymorphism of the specific yeast background we originally 
chose (W303), we repeated all of our experiments in a second genetic background (74D-694). [PSI maintenance results were entirely congruent between the two backgrounds (Fig. S6).

\section{atDjBs cannot substitute for Sis1 in Hsp104-mediated elimination of strong $\left[\mathrm{PSI}^{+}\right]$variants}

As all six tested atDjBs equally maintained strong $\left[\mathrm{PSI}^{+}\right]$variants, we next investigated whether another Sis 1 function may have been conserved among all or any plant ortholog. $\left[P S I^{+}\right]$, but not other prions, is efficiently eliminated from cell populations in a JDP-regulated process when Hsp104 is overexpressed $(43,55,56)$. Because Sis1 is essential for the elimination of strong, but not the weak $\left[\mathrm{PSI}^{\dagger}\right]$ variant, we asked whether atDjB1-6 could substitute for Sis1. Cells bearing strong $\left[\mathrm{PSI}^{+}\right]$ variants in both genetic backgrounds and expressing individual atDjB1-6 proteins in place of Sis 1 were transformed with an overexpression construct of Hsp104 (GPD-HSP 104). Selected transformants were patched on rich YPD media to check for prion maintenance. Interestingly, none of the tested atDjBs were able to substitute for Sis1 in Hsp104-mediated curing of strong $\left[\mathrm{PSI}^{+}\right]$as shown by the colony color assay (Fig. 7A). In contrast to strong variants, we recently found that the curing of weak $\left[P S I^{+}\right]$ variants by Hsp104 appears to be Sis1 independent (43). Accordingly, we would expect that the curing of these variants would be unaffected by the replacement of Sis 1 with an atDjB protein. To test this, strains expressing atDjB2 and atDjB3 that can maintain the weak $\left[P S I^{+}\right]^{\mathrm{Sc} 37}$ variant were also examined for Hsp104-mediated curing. As expected, the prion was eliminated in both instances as indicated by colony color (Fig. 7B) and SDDAGE (Fig. 7C). These results suggest that plant Sis1 orthologs are deficient in the specific Sis1 functionality needed for Hsp104 to eliminate strong $\left[\mathrm{PSI}^{+}\right]$variants.

\section{Six atDjBs differentially maintain $\left[R N Q^{+}\right]$and segregate into three sets of isofunctional pairs}

The observed functional diversity among atDjB1-6, revealed in the $\left[P S I^{+}\right]$maintenance experiments, prompted us to ask whether these proteins can also propagate the $\left[R N Q^{+}\right]$prion, as $\left[R N Q^{+}\right]$propagation requires different functions of Sis1 than either strong or weak $\left[P S I^{+}\right]$variants $(46,50)$. To examine the ability of atDjBs for maintenance of $\left[R N Q^{+}\right]$, we used a well-studied variant of $\left[R N Q^{+}\right]$called $\left[R N Q^{+}\right]^{\mathrm{STR}}(31)$. After plasmid-shuffling using 5-FOA to express individual atDjB1-6 proteins in $\mathrm{W} 303$ sis $1 \Delta,\left[R N Q^{+}\right]^{\text {STR }}$ cells, these strains were then transformed with plasmids expressing a Rnq1-GFP fusion construct. The presence of $\left[R N Q^{+}\right]$in these cells can readily be detected by fluorescent foci in cells expressing Rnq1-GFP, whereas in $\left[r n q^{-}\right]$cells, the fluorescence remains diffuse and homogeneously distributed throughout the cytoplasm. In contrast to strong $\left[P S I^{+}\right]$, atDjB1-6 differed in their ability to maintain the $\left[R N Q^{+}\right]$prion, yet the pattern of maintenance was also unlike that of weak $\left[\mathrm{PSI}^{+}\right]^{\mathrm{Sc} 37}$. Cells expressing atDjB1-4 as the only Sis1 ortholog, exhibited fluorescent foci like the endogenous Sis1-expressing cells, indicative of $\left[R N Q^{+}\right]$maintenance. In contrast, atDjB5 and atDjB6 cells exhibited diffuse Rnq1-GFP fluorescence about the cytoplasm, indicative of [ $\left.r n q^{-}\right]$cells (Fig. 8A), suggesting that atDjB5 and atDjB6 were unable to propagate the $\left[R N Q^{+}\right]$prion in the $\mathrm{W} 303$ background. SDDAGE analysis using an anti-Rnq1 antibody confirmed our microscopy observations: high molecular weight $\left[R N Q^{+}\right]$aggregates were observed only in cells expressing atDjB1-4. Cells expressing either atDjB5 or atDjB6 exhibited only the monomeric form of Rnq1, indicating that they are $\left[\mathrm{rnq}^{-}\right]$(Fig. 8B). Once again, we repeated these experiments using SDDAGE in the 74D-694 background with identical results (Fig. S7). Put together, our results show that the six tested Sis1 orthologs may have distinct aggregate remodeling functionalities in A thaliana.

\section{atDjB1-6 differentially substitute for Ydj1 in budding yeast}

Sis1 shares significant functional overlap with Ydj1, the major Class I JDP of yeast (57). The C-terminal domains of one or the other protein are required for the viability of yeast cells (58). Ydj1 performs several housekeeping chaperone functions and is important for growth at high temperatures (59). $y d j 1 \Delta$ cells grow slowly at $25^{\circ} \mathrm{C}$ and are dead at $34^{\circ} \mathrm{C}$. The slow growth phenotype of $y d j 1 \Delta$ is rescued by overexpressing Sis1 (60). To test for another potentially-conserved function of Sis1, specifically one that is dependent on Sis1's C-terminal domain, we asked whether atDjB1-6 can also rescue the slow growth phenotype of $y d j 1 \Delta$. To address this, $y d j 1 \Delta$ cells were transformed with plasmids expressing individual atDjBs. Interestingly, while all these JDPs rescued the essential functions of Sis 1 , only atDjB1-4 could rescue the slow growth of the $y d j 1 \Delta$ strain (Fig. 9A). To more rigorously assess the functional differences within atDjB1-6, we tested their ability to rescue the lethality of sis $1 \Delta y d j 1 \Delta$ following the loss of [URA3-SISI]. As expected, only atDjB1-4, could substitute for Sis 1 deficiency in 
the absence of Ydj1. Previously, it has been shown that a Sis $1_{1-121}$ fragment (which lacks the C-terminal domains) is sufficient to rescue sis $1 \Delta$ cells but only in the presence of full-length Ydj1 (58). Plasmids expressing different atDjBs were first transformed into sis 1 $\Delta y$ dj $1 \Delta$ [URA3-SIS1] pRS313-Sis $1_{1-121}$ cells and then counterselected against the URA3-SIS1 plasmid on 5-FOA plates. We found that atDjB1-4 rescued growth of sis $1 \Delta y d j 1 \Delta$ pRS313-Sis $1_{1-121}$ cells like Sis1 at $30^{\circ} \mathrm{C}$, but, again, atDjB5 and atDjB6 did not (Fig. 9B; 9C). These results indicate that atDjB5 and atDjB6 are functionally distinct from other atDjBs.

\section{The glycine-rich regions determine the functional specificity of atDjBs toward the $\left[R N Q^{+}\right]$prion}

Since all the atDjBs rescued the essential functions of Sis1, we hypothesized that the functional differences observed in atDjB5 and atDjB6, including their inability to maintain $\left[R N Q^{+}\right]$prion, may be due to differences between the glycine-rich regions of these proteins and these same regions in other orthologs which retain more Sis1 functions, like atDjB2.Previous reports have also demonstrated that the glycine-rich region of Sis1 plays a critical role in the propagation of $\left[R N Q^{+}\right](32,61)$. Additionally, atDjB2 and atDjB5 have significant differences in their glycine-rich regions (Fig. S8). As a first step toward identifying the specific sequence features that give rise to the distinct functionalities conserved among some but not other atDjBs, we asked whether the glycine-rich region can direct atDjB chaperone action. To do this, we made two chimeras of atDjB5 with either the glycine/phenylalanine and glycine/methionine $(\mathrm{G} / \mathrm{F}$ and $\mathrm{G} / \mathrm{M})$ (Chimera $\mathrm{A}$ ) or only the $\mathrm{G} / \mathrm{F}$ (Chimera $\mathrm{B}$ ) region(s) of atDjB2 (Fig. 10A). These chimeras allowed us to ask whether sequence differences in the glycine-rich region are contributing to the differential aggregate remodeling properties among the Arabidopsis atDjBs.

Before analyzing the aggregate remodeling properties of the chimeras, we verified if they behaved like atDjB2 in growth assays by testing the ability of Chimeras A and B to rescue the lethality of sis $1 \Delta$, sis $1 \Delta y d j 1 \Delta$, or sis $1 \Delta y d j 1 \Delta$ pRS313-Sis $1_{1-121}$ strains. While Chimera A could substitute for Sis 1 deficiency in all strains, Chimera B supported the growth of only sis $1 \Delta$ but not of sis $1 \Delta y d j 1 \Delta$ or sis $1 \Delta y$ dj1 $1 \Delta$ pRS313-Sis $1_{1-121}$ double deletion strains (Fig. 10B; 10C; 10D). HA-tagging followed by western analysis revealed that these proteins are expressed at similar levels in yeast cells, so this functional difference is likely not due to differences in protein quantities (Fig. 10E). Next, we determined the ability of the chimeras to propagate $\left[R N Q^{+}\right]$. sis $1 \Delta\left[R N Q^{+}\right]$cells expressing atDjB2, atDjB5, Chimera A, or Chimera B were transformed with a plasmid expressing Rnq1-GFP. Chimera A maintained $\left[R N Q^{+}\right]$like atDjB2 as indicated by distinct fluorescent foci (Fig. 10F). However, Chimera $\mathrm{B}$, which only has the GF region of atDjB2, was unable to propagate $\left[R N Q^{+}\right]$(Fig. 10F). These results were also confirmed by SDDAGE (Fig. 10G). Finally, we asked whether the glycine-rich regions of atDjB2 also conferred the ability to propagate weak $\left[\mathrm{PSI}^{+}\right]^{\mathrm{Sc} 37}$ to the atDjB5 protein. Consistent with the previous results for atDjB5, both chimeras were only able to support the strong but not the weak $\left[\mathrm{PSI}^{+}\right]$variants, as confirmed by colony color assay (Fig. S9A) and SDDAGE (Fig. S9B) in W303 cells and in the 74D-694 background (Fig. S9C; S9D) as well. Collectively, these results indicate that the biochemical differences among atDjBs that allow the rescue of sis $1 \Delta y d j 1 \Delta$ strains, and propagation of the $\left[R N Q^{+}\right]$prion, are specifically determined by the glycine-rich regions of these proteins.

\section{Discussion}

Here we report the identification and characterization of aggregate remodelling Class II JDPs (atDjBs) in A. thaliana. Results presented in this study demonstrate that atDjBs interact with heatinduced protein aggregates and co-localize with the major disaggregase Hsp101, at distinct protein aggregate centers (PACs) in plant cells. The fact that these proteins displayed specificity towards different types of aggregates suggests that plants may employ different JDPs to specify and modulate the aggregate remodelling activities of the Hsp70-Hsp100 bi-chaperone system.

Formation of cytotoxic protein aggregates is the hallmark of cellular stress, particularly, high temperature $(62,63)$. Additionally, environmental stresses like UV exposure, low temperature, and high salt also induce protein misfolding and aggregation in plant cells $(64,65)$. Perhaps unsurprisingly, while several chaperones are heat-shock regulated (66), some are either constitutively expressed or regulated by salt, cold, osmotic, and oxidative stress (67). atDjBs studied here exhibited variability in their expression profiles during different developmental stages and stress conditions suggesting that besides mitigating protein misfolding and aggregation under stress conditions, atDjBs may also play important roles in plant growth and development under non-stress regimes. 
Specialized JDPs recruit Hsp70 to the aggregates and concomitantly stimulate their weak ATPase activity (68). Hsp70 then recruits and activates Hsp100 to extract proteins from a variety of protein aggregates, a crucial step in aggregate remodeling $(69,70)$. A Similar, yet complex scenario emerges in plants. While atDjB1-6 co-localized with Hsp101 to distinct heat-induced PACs in isolated Arabidopsis protoplasts, this might not be physiological, as out of the six JDPs analyzed here, only atDjB2 and atDjB3 were heat-inducible. Because Hsp101 is also heat-inducible, it is plausible that among the six atDjBs, only atDjB2 and atDjB3 play specialized roles in regulating the disaggrergase activity of Hsp70-Hsp100 chaperone machines in response to high temperature. At this point we cannot rule out the possibility that atDjB1, atDjB4, atDjB5 and atDjB6 cooperate with Hsp101 in vivo. It is possible that these atDjBs drive the disaggregase activity of Hsp70s without Hsp100. Such standalone aggregate remodeling systems are known to exist in metazoans which lack a Hsp100 homolog (except in the mitochondria) (71).

All the atDjBs we fully analyzed here rescued the essential functions of Sis 1 in a sis $1 \Delta$ strain. This requires the Hsp70 co-chaperone activity, as mutations in the critical HPD motif within the Jdomain of atDjB1 abolishes their ability to rescue a sis $1 \Delta$ strain (44). Besides performing an unknown essential function, Sis 1 also remodels different types of protein aggregates, including prions in yeast $(35,72,73)$. Distinct domains of Sis1 are important for the maintenance of different yeast prions $(31$, 43). Interestingly, atDjB1-6 exhibited different aggregate remodeling properties in yeast, suggesting towards a subfunctionalization of the aggregate remodeling activities within this set of proteins. Except for the glycine-rich (G/F-G/M) region following the J-domain, atDjBs show significant similarity with each other as well as with their yeast homolog Sis1. The G/F region of Sis1 is required for $\left[R N Q^{+}\right]$ maintenance (32). Moreover, this region shares a functional overlap with the G/M region and carries determinants for Sis1's specificity (61). Consistent with this, results from protein chimera experiments indicate that variations in the glycine-rich region of atDjBs not only defines their functionality but also their specificity towards different types of aggregates. Most notably, replacement of the G/F+G/M-rich region of atDjB5, which cannot maintain $\left[R N Q^{+}\right]$, with those from atDjB2 imparted the ability to propagate $\left[R N Q^{+}\right]$. However, the replacement of only the G/F-rich region was insufficient, indicating that both glycine-rich regions are required. The fact that the chimera with both glycine-rich regions substituted, rescued the lethality of sis $1 \Delta y d j 1 \Delta$ and sis $1 \Delta y d j 1 \Delta$ pRS313-Sis $1_{1-121}$ strains also implies that the glycine-rich regions in at least some atDjBs may have functional redundancy with their $\mathrm{C}$ terminal client binding domains. This is true for Sis 1 as well. While complete deletion of the $\mathrm{G} / \mathrm{F}$ region results invariantly in the loss of $\left[R N Q^{+}\right]$, point mutations in the unique region (amino acids 101-113) in the G/F result in $\left[R N Q^{+}\right]$loss only in the absence of Sis1's C-terminal domains (61). Interestingly, despite substituting for Sis1 in all other functions, the fully-swapped G/F and G/M chimera did not propagate weak $\left[P S I^{+}\right]^{\mathrm{Sc} 37}$, indicating that some sort of cooperativity between the glycine rich region and the CTD, possibly to mediate a bipartite interaction with Hsp70 (74)may be necessary for the remodeling of some aggregate.

Overexpression of Hsp104 is known to rapidly cure strong variants of $\left[\mathrm{PSI}^{+}\right]$from cell populations by a highly-debated mechanism, requiring Sis 1 (54). Strikingly, all six orthologs examined were deficient in replacing Sis1 in this process which is congruent with previous findings for both Hdj1 and Droj1 $(43,54)$. Thus, regarding Hsp104-overexpression mediated aggregate remodeling resulting into prion loss, all 8 higher eukaryotic Sis1 orthologs that have been studied specifically lack this ability. These eukaryotic orthologs, together with Sis1, now form an exciting set of sequence-similar proteins with diverse but clearly defined aggregate remodeling functionalities. While no atDjB behaved exactly like Sis1, our data resolved the six orthologs into 3 sets of isofunctional pairs: atDjB2/3 maintained almost all prions tested, most similar to Sis 1 ; atDjB1/4 maintained $\left[R N Q^{+}\right]$and strong $\left[P S I^{+}\right]$variants but not $\left[P S I^{+}\right]^{\mathrm{Sc} 37}$, like the human and Drosophila orthologs Hdj1 and Droj1 $(31,43)$; and atDjB5/6 fail to maintain any prion except strong $\left[\mathrm{PSI}^{+}\right]$variants, similar to the Sis1 mutant that disrupts the bipartite interaction between Sis1 and Hsp70 (75).

Put together, this study demonstrates that compared to bacteria and budding yeast which have one each (CbpA and Sis1 respectively), or even complex metazoans like humans which have three (DNAJB1, DNAJB4 and DNAJB5) (68), Sis1-like Class II JDPs have proliferated in plants with seven in Rice and potato, nine in maize (unpublished results) and eight in A. thaliana (76), which could result in a highly complex network of aggregate-remodeling chaperone systems. There is a growing list of plant proteins that show amyloid behaviour. This includes the naturally occurring monellin in 
Dioscoreophyllum cumminsii, transglutaminase (TGZ) from maize, seed storage proteins in pea, soybean and wheat, defensin protein in radish and coconut, and prohevein protein from rubber tree (7786). Recently flowering pathway proteins, Luminidependens (LD), Flowering Locus PA (FPA) and Flowering Locus CA (FCA) from A. thaliana were shown to behave like prions in yeast cells (87). Additionally, studies show that several plant proteins harbour amino acid clusters that are prone to aggregate $(87,88)$. Some potential prion-forming proteins may have roles in regulating different aspects of plant growth and development $(87,89)$. While the present study identifies stress associated JDPs that might collaborate with Hsp101 to solubilize heat-induced protein aggregates, it remains to be seen if they also remodel different amyloid aggregates thereby acting as epigenetic modifiers of plant growth and development in Arabidopsis.

\section{Experimental procedures:}

\section{In silico analysis}

atDjB domain architecture was predicted by SMART database (http://smart.emblheidelberg.de/) (90). Models for domain organization were created by IBS (http://ibs.biocuckoo.org/index.php) (91). Secondary structures were predicted using SWISS-MODEL (https://swissmodel.expasy.org) (92). EMBOSS needle was used for the identification of sequence similarity and identity between Sis1 orthologs (https://www.ebi.ac.uk/Tools/psa/emboss_needle/) (93).

\section{Plasmid construction for yeast complementation}

Open reading frames (ORFs) corresponding to full-length Sis1 orthologs were PCR amplified from a pooled $A$. thaliana cDNA made from RNA isolated from stressed and unstressed shoots, roots, and inflorescence. S. cerevisiae SIS1 was amplified from yeast genomic DNA. atDjB1, atDjB2, atDjB3, atDjB4, atDjB5 and atDjB6 encoding genes were cloned either into HIS3-marked pRS413 or TRP1marked pRS414 yeast expression vectors under the TEF1 promoter (50) in Bam-HI and Sal-I sites. To generate N-terminus HA-tagged constructs, the tag was added in the forward primers before the ORF of ScSis1 in between Spe-I and Bam-HI sites and cloned into HIS3-marked pRS413 using the same reverse primer having Sal-I site. ORFs of the orthologs were subcloned in the same HA-tagged construct by releasing $\mathrm{ScSis} 1$ fragment with Bam-HI and Sal-I sites. All the constructs were confirmed by restriction digestion and sequencing.

Overlapping PCR method was used to construct Chimera A and Chimera B from atDjB2 and atDjB5 genes. A chimeric gene encoding the J-domain (aa 1 to 76 ) of atDjB5, the $\mathrm{G} / \mathrm{F}$ and $\mathrm{G} / \mathrm{M}$ regions (aa 81 to 173 ) of atDjB2 and the C-terminal domains (aa 173 to 350 ) of atDjB5 was referred to as Chimera A. A chimeric gene encoding the J-domain (aa 1 to 76 ) of atDjB5, the G/F region (aa 81 to 117) of atDjB2, and part of the glycine-rich region and C-terminal domains (aa 118 to 350) of atDjB5 was called Chimera B. These were cloned into TRPl-marked pRS414 yeast expression vectors under the TEF1 promoter with Bam-HI and Sal-I sites. To compare the expression levels of the Chimeric proteins, they were subcloned in previously used pRS413-HA-Sis 1 construct having N-terminal HAtag by releasing Sis1 fragment with Bam-HI and Sal-I sites.

Protein fusion constructs were generated for subcellular localization analysis, the open reading frames having attB1 and attB2 sites for atDjB1, atDjB2, atDjB3, atDjB4, atDjB5, and atDjB6 without a stop codon and Hsp101 with a stop codon were amplified from Arabidopsis cDNA. PCR fragments were then cloned into Gateway pDONR207 vector (Invitrogen, Thermo Fisher Scientific) by BP reaction to produce entry clones. The entry clones were confirmed through sequencing. atDjB1-6 pDONR207 entry clones were used in LR reaction with the Gateway-compatible plant binary vector pGWB5 (94) containing the 35S promoter and the C-GFP fragment to produce destination clones. Similarly, the Hsp101 pDONR207 entry clone was used in LR reaction with Gateway-compatible plant binary vector pGWB661 (95)containing the 35S promoter and the N-RFP fragment to produce destination clones. The BP and LR reactions were done as described in manufacturer's manual (Invitrogen, Thermo Fisher Scientific). All primer sequences are listed in supporting Table 1.

\section{Protein purification and Antibody generation}


atDjB1-C-term (aa 157 to 335) was amplified from pRS413-atDjB1 and cloned into pET28a(+) bacterial expression vector using Bam-HI and Xho-I sites. Protein was expressed from E. coli strain (Rosetta) and purified using Ni-NTA affinity chromatography according to the manufacturer's instructions (Qiagen Cat No./ID: 30210). Purified protein was used as an immunogen to raise polyclonal antibody in rabbits at a local commercial facility (DPL, Bhopal, India)

\section{Yeast methods}

Haploid S. cerevisiae W303 or 74D-694 derived ydj1D (ydj1::HIS3), sis $1 \Delta$ (sis $1:: L E U 2)$ and sis $1 \Delta y$ dj $1 \Delta$ (sis $1:: L E U 2$, ydj $1:: H I S 3$ ) strains previously described (44) were used throughout the study. Yeast strains with sis $1 \Delta$ harbored a URA3-marked plasmid expressing the wild-type SIS1 gene (pRS316SIS1). For testing the ability of atDjBs to complement the in vivo functions of Sis1, we used 5fluoroorotic acid (5-FOA) plasmid shuffling (96). atDjB1-6 cloned in yeast expression vectors were transformed into W303 or 74D-694 sis $1 \Delta$ andsis $1 \Delta y d j 1 \Delta$ strains and counterselection of pRS316-SIS1 was done on medium containing 5-FOA. Yeast strains bearing $\left[P S I^{+}\right]^{\mathrm{Sc} 4},\left[P S I^{+}\right]^{\mathrm{Sc} 37},\left[P S I^{+}\right]^{\mathrm{VL}},\left[P S I^{+}\right]^{\mathrm{VH}}$, or $\left[R N Q^{+}\right]^{\text {STR }}$ prions were used to study the aggregate remodeling properties of atDjB1-6through plasmid shuffling as described previously (31). $\left[\mathrm{PSI}^{+}\right]$maintenance was observed through the colony color assay. Briefly, all the selected transformants after counterselection were patched on YPD for prion maintenance. If Sup35 is soluble or cells are in [psi'] state, the colonies look red due to accumulation of red intermediate resulting from the block in adenine biosynthesis. When Sup35 is in the aggregated state, i.e., $\left[\mathrm{PSI}^{+}\right]$, the yeast colonies look white or pink due to complete or partial restoration of adenine biosynthesis (39). $\left[R N Q^{+}\right]$maintenance in cells were observed directly under Zeiss, Apotome at Excitation/Emission $\sim 361 / 497 \mathrm{~nm}$ at 100X magnification following transformation by (pRS413-Rnq1GFP) plasmid (37). To create [ $\left.\mathrm{prion}^{-}\right]$strains or to confirm prion maintenance, prion-bearing cells were treated with the Hsp 104 inhibitor guanidine hydrochloride (3mM) in YPD liquid medium which readily cures $\left[P S I^{+}\right]$and $\left[R N Q^{+}\right]$. For examining prion loss or curing by Hsp104 overexpression, a plasmid overexpressing Hsp104 was transformed in all the prion bearing strains and incubated on selective medium to detect prion maintenance as described previously (43).

\section{Preparation of Soluble and Insoluble Protein Fractions}

Fractionation of soluble and heat-denatured proteins was done as described previously (27). Briefly, two-week-old Arabidopsis seedlings grown on 1/2 MS plates were either untreated (control) or heat stressed as described above. For each sample, $0.7 \mathrm{~g}$ of plant tissue was harvested, and a crude protein extract was prepared using $1 \mathrm{~mL}$ of protein isolation buffer $(25 \mathrm{mM}$ HEPES, $\mathrm{pH} 7.5,200 \mathrm{mM}$ $\mathrm{NaCl}, 0.5 \mathrm{mM}$ EDTA, $0.1 \%(\mathrm{v} / \mathrm{v})$ Triton X-100, $5 \mathrm{mM} \varepsilon$-amino- $N$-caproic acid, and $1 \mathrm{mM}$ benzamidine-HCl). After grinding the sample using a mortar and pestle, samples were further homogenized with a Dounce glass tissue grinder for $1 \mathrm{~min}$ on ice. The crude protein extract was transferred to a microcentrifuge tube, and $500 \mu \mathrm{L}$ was used for separation into soluble and insoluble fractions, while $300 \mu \mathrm{L}$ was added to $100 \mu \mathrm{L}$ of 4 X SDS-PAGE sample buffer $(8 \%$ [w/v] SDS, $46 \%$ $[\mathrm{v} / \mathrm{v}]$ glycerol, $20 \%$ [v/v] $\beta$-mercaptoethanol, $250 \mathrm{mM}$ Tris, $\mathrm{pH} 6.8$, and $0.01 \%$ [w/v] Bromophenol Blue). For fractionation, samples were spun in a table top centrifuge at $16,100 \mathrm{~g}$ for $15 \mathrm{~min}$. The supernatant was collected in a fresh microcentrifuge tube, and $300 \mu \mathrm{L}$ of supernatant was added to 100 $\mu \mathrm{L}$ of $4 \times$ SDS-PAGE sample buffer for SDS-PAGE and immunoblot analysis. To facilitate washing of the insoluble fraction, $0.1 \mathrm{~g}$ of quartz salt (Sigma-Aldrich) was added to the pellet fraction, and samples were washed seven times with $1 \mathrm{~mL}$ of protein isolation buffer. For each wash, the pellet was resuspended by pipetting and intermittent mixing, and the samples were centrifuged subsequently at $16,100 \mathrm{~g}$ for $15 \mathrm{~min}$. After the washes, the insoluble fraction was washed once with PIB without Triton$\mathrm{X} 100$. The pellet fraction was resuspended in $250 \mu \mathrm{L}$ of PIB and along with equal volume of $2 \mathrm{X}$ SDSPAGE sample buffer, creating a total volume of $500 \mu \mathrm{L}$. Samples were spun for $30 \mathrm{~s}$ at $1,500 \mathrm{~g}$, and the soluble fraction was transferred to a new microcentrifuge tube.

\section{Protein Analyses}

Total protein from yeast was isolated from cultures in log phase by treating cells with $0.1 \mathrm{~N}$ $\mathrm{NaOH}$ and resuspending in SDS sample buffer $(62.5 \mathrm{mM}$ Tris $\cdot \mathrm{HCl}, \mathrm{pH} 6.8,5 \%$ glycerol, $2 \% \mathrm{SDS}, 2 \%$ $\beta$-mercaptoethanol, and $0.01 \%$ bromophenol blue). Proteins were resolved on $12 \%$ SDS-PAGE, 
electroblotted on PVDF membrane (Bio-Rad), and for immunodetection probed with anti-HA antibody (Sigma-Aldrich) or an anti-TBP antibody (a kind gift from Prof R. S. Tomar, IISER Bhopal, India).

Semi-denaturing detergent agarose gel electrophoresis (SDDAGE), a method for resolving detergent-resistant aggregates, was used to confirm the presence of $\left[R N Q^{+}\right]$and $\left[\mathrm{PSI}^{+}\right]$as previously described (31). Briefly, cells were lysed by vortexing at $4^{\circ} \mathrm{C}$ with sterile glass beads. Following centrifugation at $4{ }^{\circ} \mathrm{C}$, cleared lysates were mixed with SDS loading buffer and incubated at $25^{\circ} \mathrm{C}$ for 78 minutes. Aggregates were resolved in a $1 \%$ agarose gel made in $1.5 \%(\mathrm{w} / \mathrm{v})$ Tris-glycine and $0.1 \%$ SDS (SeaKem Gold PFGE agarose). Proteins were transferred to a nitrocellulose membrane at $1 \mathrm{~A}$ for $1 \mathrm{~h}$ in a Tris-glycine/methanol buffer. Prion aggregates were visualized by performing western analysis using antibodies specific for either Rnq1 or Sup35 (gifts from the Craig and Tuite labs, respectively).

Total, soluble and pellet plant protein fractions were separated by SDS-PAGE on 13\% SDSPAGE, electroblotted on PVDF membrane (Bio-Rad), and processed for immunodetection. Primary antibody dilutions and Agrisera order numbers were as follows: CI sHSPs (1:3,000; AS07 254); GAPC (1:1000; AS15 2894), and C-term atDjB1 (generated in the laboratory; 1:1,000). Blots prepared for fluorescent detection were incubated with goat anti-rabbit secondary antibody, Alexa Fluor Plus 680 (1:20,000; A32734-Invitrogen), and detected using a Li-Cor Odyssey.

\section{Plant assays}

The Col-0 ecotype of Arabidopsis thaliana was used in all experiments. Seeds were surface sterilized and grown on plates with 1/2MS Basal Salt Mixture (M5524: Sigma), MES (0.05\%) [(2-(Nmorpholino) ethane sulfonic acid], 1\% (w/v) sucrose, and 0.7\% agar (PCT0901: HIMEDIA), stratified at $4{ }^{\circ} \mathrm{C}$ for $48 \mathrm{~h}$ in the dark and then transferred to a Percival LED22C 8 growth cabinet at $22^{\circ} \mathrm{C}$ Day $/ 18^{\circ} \mathrm{C}$ Night and $70 \%$ humidity (light intensity $120 \pm 20 \mu \mathrm{mol} \mathrm{m}^{-2} \mathrm{~s}^{-1}$, 16-h light:8-h dark cycle). After germination, 20-25 days plantlets were subjected to various stress treatments (heat stress by $37^{\circ} \mathrm{C}$ for $1 \mathrm{~h}$, cold stress by $4^{\circ} \mathrm{C}$ for $24 \mathrm{~h}$, mannitol $(150 \mathrm{mM})$ for $24 \mathrm{~h}$, salt stress $(150 \mathrm{mM} \mathrm{NaCl})$ for $24 \mathrm{~h}$, and mechanical stress by puncturing the leaves and leaving them on media for $1 \mathrm{~h}$ ).

For protoplast isolation 15-day old Arabidopsis seedlings were transferred to the soil and grown under short day conditions in a Percival LED22C8 growth cabinet at $22^{\circ} \mathrm{C} \mathrm{Day} / 18^{\circ} \mathrm{C}$ Night and $70 \%$ humidity (light intensity $120 \pm 20 \mu \mathrm{mol} \mathrm{m}^{-2} \mathrm{~s}^{-1}$, 10-h light:14-h dark cycle). 3 to 4-week-old plants were used for protoplast isolation and transfection.

The atDjB1-B6 C-GFP fusion constructs (pGDW5) were transformed into protoplasts by using polyethylene glycol-mediated transformation as described previously (97). Hsp101 N-RFP fusion construct (pGWB661) was used as protein aggregate centres (PAC) marker for co-localization studies. Images were taken with an Olympus FluoView-3000 confocal inverted laser scanning confocal imaging system (Olympus, Japan). Excitation and emission wavelengths Ex488/Em500-520, Ex558/Em580600, and Ex594/Em630-700 were used for GFP, RFP and Cy5, respectively. The images acquired from the confocal microscope were analyzed using ImageJ software (98). Separate channel images were assembled using Adobe Photoshop CS5.1.

\section{RNA extraction and quantitative reverse transcription PCR}

Total RNA was extracted from plant seedling samples using TRizol reagent (SIGMA) and reverse transcribed to make cDNA after DNase I treatment using iScript cDNA synthesis kit (Bio-Rad) following the manufacturer's instructions. Real-time PCR was performed in a CFX connect 96-well real-time system using iTaq universal $\mathrm{SyBr}$ green Supermix (BioRad). Data analysis was done according to MIQE guidelines (99). Reference gene used was ACTIN for normalization.

\section{Data availability:}

All the data reported is in the manuscript. 


\section{Acknowledgments:}

We thank Elizabeth Craig (University of Wisconsin-Madison), Mick Tuite (University of Kent), and R.S. Tomar (IISER Bhopal, India) for yeast strains, plasmids, and antibodies, Y.T. thanks the Ministry of Science and Technology for Council of Scientific and Industrial Research (CSIR) fellowship, S.S.L. thanks the Indian Ministry of Human Resource Development for a Graduate Aptitude Test in Engineering fellowship. We are grateful to Fund for Improvement of Science \&Technology Infrastructure in Higher Educational Institutions (FIST) for providing live cell imaging system to the IISER Bhopal Microscopy Central Facility.

\section{Funding and additional information:}

This work was supported by funds from the Science and Engineering Research Board (EMR/ 2015/001213), intramural funds from IISER Bhopal to C.S.; the Lafayette College Chemistry Department, the EXCEL research scholarship program, the Camille and Henry Dreyfus Foundation (Award No. TH-18-017), and the National Institute of General Medical Sciences of the National Institutes of Health (Award No. R15GM110606), awarded to J.K.H. The content is solely the responsibility of the authors and does not necessarily represent the official views of the National Institutes of Health.

Conflict of interest: The authors declare that they have no conflicts of interest with the contents of this article.

\section{References:}

1. Hipp, M. S., Kasturi, P., and Hartl, F. U. (2019) The proteostasis network and its decline in ageing. Nature Reviews Molecular Cell Biology. 20, 421-435

2. Chen, B., Retzlaff, M., Roos, T., and Frydman, J. (2011) Cellular strategies of protein quality control. Cold Spring Harbor Perspectives in Biology. 10.1101/cshperspect.a004374

3. Campioni, S., Mannini, B., Zampagni, M., Pensalfini, A., Parrini, C., Evangelisti, E., Relini, A., Stefani, M., Dobson, C. M., Cecchi, C., and Chiti, F. (2010) A causative link between the structure of aberrant protein oligomers and their toxicity. Nature Chemical Biology. 6, 140-147

4. Yoshimura, Y., Lin, Y., Yagi, H., Lee, Y.-H., Kitayama, H., Sakurai, K., So, M., Ogi, H., Naiki, H., and Goto, Y. (2012) Distinguishing crystallike amyloid fibrils and glass-like amorphous aggregates from their kinetics of formation. Proceedings of the National Academy of Sciences. 109, 14446

5. Mogk, A., Bukau, B., and Kampinga, H. H. (2018) Cellular handling of protein aggregates by disaggregation machines. Molecular Cell. 69, 214226

6. Labbadia, J., and Morimoto, R. I. (2015) The biology of proteostasis in aging and disease. Annual Review of Biochemistry. 84, 435-464

7. Battisti, David. S., and Naylor, R. L. (2009) Historical warnings of future food insecurity with unprecedented seasonal heat. Science. 323, 240 
8. Mittler, R., Finka, A., and Goloubinoff, P. (2012) How do plants feel the heat? Trends in Biochemical Sciences. 37, 118-125

9. Kotak, S., Larkindale, J., Lee, U., von Koskull-Döring, P., Vierling, E., and Scharf, K.-D. (2007) Complexity of the heat stress response in plants. Current Opinion in Plant Biology. 10, 310-316

10. Al-Whaibi, M. H. (2011) Plant heat-shock proteins: a mini review. Journal of King Saud University - Science. 23, 139-150

11. Parsell, D. A., and Lindquist, S. (1993) The function of heat-shock proteins in stress tolerance: degradation and reactivation of damaged proteins. Annual Review of Genetics. 27, 437-496

12. Kim, Y. E., Hipp, M. S., Bracher, A., Hayer-Hartl, M., and Ulrich Hartl, F. (2013) Molecular chaperone functions in protein folding and proteostasis. Annual Review of Biochemistry. 82, 323-355

13. Haslbeck, M., and Vierling, E. (2015) A first line of stress defense: small heat shock proteins and their function in protein homeostasis. Journal of Molecular Biology. 427, 1537-1548

14. Lee, G. J., and Vierling, E. (2000) A small heat shock protein cooperates with heat shock protein 70 systems to reactivate a heatdenatured protein. Plant Physiology. 122, 189

15. Kampinga, H. H., and Craig, E. A. (2010) The HSP70 chaperone machinery: J proteins as drivers of functional specificity. Nature Reviews Molecular Cell Biology. 11, 579-592

16. Winkler, J., Tyedmers, J., Bukau, B., and Mogk, A. (2012) Hsp70 targets Hsp100 chaperones to substrates for protein disaggregation and prion fragmentation. Journal of Cell Biology. 198, 387-404

17. Tipton, K. A., Verges, K. J., and Weissman, J. S. (2008) In vivo monitoring of the prion replication cycle reveals a critical role for Sis 1 in delivering substrates to Hsp104. Molecular Cell. 32, 584-591

18. Doyle, S. M., and Wickner, S. (2009) Hsp104 and ClpB: protein disaggregating machines. Trends in Biochemical Sciences. 34, 40-48

19. Queitsch, C., Hong, S.-W., Vierling, E., and Lindquist, S. (2000) Heat shock protein 101 plays a crucial role in thermotolerance in Arabidopsis. The Plant Cell. 12, 479

20. Sanchez, Y., and Lindquist, S. L. (1990) HSP104 required for induced thermotolerance. Science. 248, 1112

21. McLoughlin, F., Basha, E., Fowler, M. E., Kim, M., Bordowitz, J., Katiyar-Agarwal, S., and Vierling, E. (2016) Class I and II small heat shock proteins together with HSP101 protect protein translation factors during heat stress. Plant Physiology. 172, 1221

22. Zhong, L., Zhou, W., Wang, H., Ding, S., Lu, Q., Wen, X., Peng, L., Zhang, L., and Lu, C. (2013) Chloroplast small heat shock protein HSP21 interacts with plastid nucleoid protein pTAC5 and is essential for chloroplast development in Arabidopsis under heat stress. The Plant Cell. 25, 2925

23. Perez, D. E., Hoyer, J. S., Johnson, A. I., Moody, Z. R., Lopez, J., and Kaplinsky, N. J. (2009) BOBBER1 is a noncanonical Arabidopsis small heat shock protein required for both development and thermotolerance. Plant Physiology. 151, 241 
24. Su, P.-H., and Li, H. (2008) Arabidopsis stromal 70-kD heat shock proteins are essential for plant development and important for thermotolerance of germinating seeds. Plant Physiology. 146, 1231

25. Hong, S.-W., and Vierling, E. (2000) Mutants of Arabidopsis thaliana defective in the acquisition of tolerance to high temperature stress. Proceedings of the National Academy of Sciences. 97, 4392

26. Lee, J. H., and Schöffl, F. (1996) An Hsp70 antisense gene affects the expression of HSP70/HSC70, the regulation of HSF, and the acquisition of thermotolerance in transgenic Arabidopsis thaliana. Molecular and General Genetics MGG. 252, 11-19

27. McLoughlin, F., Kim, M., Marshall, R. S., Vierstra, R. D., and Vierling, E. (2019) HSP101 interacts with the proteasome and promotes the clearance of ubiquitylated protein aggregates. Plant Physiology. 180, 1829

28. Craig, E. A., and Marszalek, J. (2017) How Do J-Proteins Get Hsp70 to Do So Many Different Things? Trends in Biochemical Sciences. 42, 355368

29. Reidy, M., Sharma, R., Shastry, S., Roberts, B.-L., Albino-Flores, I., Wickner, S., and Masison, D. C. (2014) Hsp40s specify functions of Hsp104 and Hsp90 protein chaperone machines. PLOS Genetics. 10, e1004720-

30. Walsh, P., Bursać, D., Law, Y. C., Cyr, D., and Lithgow, T. (2004) The J-protein family: modulating protein assembly, disassembly and translocation. EMBO reports. 5, 567-571

31. Harris, J. M., Nguyen, P. P., Patel, M. J., Sporn, Z. A., and Hines, J. K. (2014) Functional diversification of Hsp40: distinct J-protein functional requirements for two prions allow for chaperone-dependent prion selection. PLOS Genetics. 10, e1004510-

32. Lopez, N., Aron, R., and Craig, E. A. (2002) Specificity of Class II Hsp40 Sis1 in Maintenance of Yeast Prion [RNQ +]. Molecular Biology of the Cell. 14, 1172-1181

33. Scior, A., Buntru, A., Arnsburg, K., Ast, A., Iburg, M., Juenemann, K., Pigazzini, M. L., Mlody, B., Puchkov, D., Priller, J., Wanker, E. E., Prigione, A., and Kirstein, J. (2018) Complete suppression of Htt fibrilization and disaggregation of Htt fibrils by a trimeric chaperone complex. The EMBO Journal. 37, 282-299

34. Lee, S., Fan, C. Y., Younger, J. M., Ren, H., and Cyr, D. M. (2002) Identification of essential residues in the type II Hsp40 Sis1 that function in polypeptide binding. Journal of Biological Chemistry. 277, 2167521682

35. Higurashi, T., Hines, J. K., Sahi, C., Aron, R., and Craig, E. A. (2008) Specificity of the J-protein Sis 1 in the propagation of 3 yeast prions. Proceedings of the National Academy of Sciences. 105, 16596

36. Hines, J. K., Higurashi, T., Srinivasan, M., and Craig, E. A. (2011) Influence of prion variant and yeast strain variation on prion-molecular chaperone requirements. Prion. 5, 238-244

37. Aron, R., Higurashi, T., Sahi, C., and Craig, E. A. (2007) J-protein cochaperone Sis1 required for generation of $\left[\mathrm{RNQ}^{+}\right]$seeds necessary for prion propagation. The EMBO Journal. 26, 3794-3803 
38. Sondheimer, N., Lopez, N., Craig, E. A., and Lindquist, S. (2001) The role of Sis1 in the maintenance of the $\left[\mathrm{RNQ}^{+}\right]$prion. The EMBO Journal. 20, 2435-2442

39. Liebman, S. W., and Chernoff, Y. O. (2012) Prions in Yeast. Genetics. 191, 1041

40. Killian, A. N., and Hines, J. K. (2018) Chaperone functional specificity promotes yeast prion diversity. PLOS Pathogens. 14, e1006695-

41. Derkatch, I. L., Chernoff, Y. O., Kushnirov, V. v, Inge-Vechtomov, S. G., and Liebman, S. W. (1996) Genesis and variability of [PSI] prion factors in Saccharomyces cerevisiae. Genetics. 144, 1375

42. Uptain, S. M., Sawicki, G. J., Caughey, B., and Lindquist, S. (2001) Strains of $[\mathrm{PSI}+]$ are distinguished by their efficiencies of prion-mediated conformational conversion. The EMBO Journal. 20, 6236-6245

43. Astor, M. T., Kamiya, E., Sporn, Z. A., Berger, S. E., and Hines, J. K. (2018) Variant-specific and reciprocal Hsp40 functions in Hsp104mediated prion elimination. Molecular Microbiology. 109, 41-62

44. Verma, A. K., Diwan, D., Raut, S., Dobriyal, N., Brown, R. E., Gowda, V., Hines, J. K., and Sahi, C. (2017) Evolutionary conservation and emerging functional diversity of the cytosolic Hsp70:J protein chaperone network of Arabidopsis thaliana. G3: Genes|Genomes|Genetics. 7, 1941

45. Masison, D. C., and Reidy, M. (2015) Yeast prions are useful for studying protein chaperones and protein quality control. Prion. 9, 174183

46. Reidy, M., and Masison, D. (2014) Yeast Prions Help Identify and Define Chaperone Interaction Networks. Current Pharmaceutical Biotechnology. 10.2174/1389201015666141103021035

47. Rodziewicz, P., Swarcewicz, B., Chmielewska, K., Wojakowska, A., and Stobiecki, M. (2014) Influence of abiotic stresses on plant proteome and metabolome changes. Acta Physiologiae Plantarum. 36, 1-19

48. Cabrera, M., Boronat, S., Marte, L., Vega, M., Pérez, P., Ayté, J., and Hidalgo, E. (2020) Chaperone-facilitated aggregation of thermo-sensitive proteins shields them from degradation during heat stress. Cell Reports. 30, 2430-2443.e4

49. Glover, J. R., and Lindquist, S. (1998) Hsp104, Hsp70, and Hsp40: a novel chaperone system that rescues previously aggregated proteins. Cell. 94, 73-82

50. Mumberg, D., Müller, R., and Funk, M. (1995) Yeast vectors for the controlled expression of heterologous proteins in different genetic backgrounds. Gene. 156, 119-122

51. Oliver, E. E., Troisi, E. M., and Hines, J. K. (2017) Prion-specific Hsp40 function: The role of the auxilin homolog Swa2. Prion. 11, 174185

52. King, C.-Y. (2001) Supporting the structural basis of prion strains: induction and identification of [PSI] variants11Edited by F. E. Cohen. Journal of Molecular Biology. 307, 1247-1260

53. Tanaka, M., Collins, S. R., Toyama, B. H., and Weissman, J. S. (2006) The physical basis of how prion conformations determine strain phenotypes. Nature. 442, 585-589 
54. Sporn, Z. A., and Hines, J. K. (2015) Hsp40 function in yeast prion propagation: Amyloid diversity necessitates chaperone functional complexity. Prion. 9, 80-89

55. Berger, S. E., Nolte, A. M., Kamiya, E., and Hines, J. K. (2020) Three J-proteins impact Hsp104-mediated variant-specific prion elimination: a new critical role for a low-complexity domain. Current Genetics. 66, 5158

56. Chernoff, Y. O., Lindquist, S. L., Ono, B., Inge-Vechtomov, S. G., and Liebman, S. W. (1995) Role of the chaperone protein Hsp104 in propagation of the yeast prion-like factor [psi+]. Science. 268, 880

57. Fan, C.-Y., Lee, S., Ren, H.-Y., and Cyr, D. M. (2003) Exchangeable Chaperone Modules Contribute to Specification of Type I and Type II Hsp40 Cellular Function. Molecular Biology of the Cell. 15, 761-773

58. Johnson, J. L., and Craig, E. A. (2001) An Essential Role for the Substrate-Binding Region of Hsp40s in Saccharomyces cerevisiae. Journal of Cell Biology. 152, 851-856

59. Caplan, A. J., and Douglas, M. G. (1991) Characterization of YDJ1: a yeast homologue of the bacterial dnaJ protein. Journal of Cell Biology. 114, 609-621

60. Caplan, A. J., Cyr, D. M., and Douglas, M. G. (1992) YDJ1p facilitates polypeptide translocation across different intracellular membranes by a conserved mechanism. Cell. 71, 1143-1155

61. Yan, W., and Craig, E. A. (1999) The Glycine-Phenylalanine-rich region determines the specificity of the yeast Hsp40 Sis1. Molecular and Cellular Biology. 19, 7751

62. Wallace, E. W. J., Kear-Scott, J. L., Pilipenko, E. V., Schwartz, M. H., Laskowski, P. R., Rojek, A. E., Katanski, C. D., Riback, J. A., Dion, M. F., Franks, A. M., Airoldi, E. M., Pan, T., Budnik, B. A., and Drummond, D. A. (2015) Reversible, specific, active aggregates of endogenous proteins assemble upon heat stress. Cell. 162, 1286-1298

63. Richter, K., Haslbeck, M., and Buchner, J. (2010) The heat shock response: life on the verge of death. Molecular Cell. 40, 253-266

64. Nakajima, Y., and Suzuki, S. (2013) Environmental stresses induce misfolded protein aggregation in plant cells in a microtubule-dependent manner. International journal of molecular sciences. 14, 7771-7783

65. Mano, J., Nagata, M., Okamura, S., Shiraya, T., and Mitsui, T. (2014) Identification of oxidatively modified proteins in salt-stressed Arabidopsis: a carbonyl-targeted proteomics approach. Plant and Cell Physiology. 55, 1233-1244

66. Verghese, J., Abrams, J., Wang, Y., and Morano, K. A. (2012) Biology of the heat shock response and protein chaperones: budding yeast (Saccharomyces cerevisiae) as a model system. Microbiology and Molecular Biology Reviews. 76, 115

67. Wang, W., Vinocur, B., Shoseyov, O., and Altman, A. (2004) Role of plant heat-shock proteins and molecular chaperones in the abiotic stress response. Trends in Plant Science. 9, 244-252

68. Kampinga, H. H., and Craig, E. A. (2010) The HSP70 chaperone machinery: J proteins as drivers of functional specificity. Nature Reviews Molecular Cell Biology. 11, 579-592 
69. Lipińska, N., Ziętkiewicz, S., Sobczak, A., Jurczyk, A., Potocki, W., Morawiec, E., Wawrzycka, A., Gumowski, K., Ślusarz, M., RodziewiczMotowidło, S., Chruściel, E., and Liberek, K. (2013) Disruption of Ionic Interactions between the Nucleotide Binding Domain 1 (NBD1) and Middle (M) Domain in Hsp100 Disaggregase Unleashes Toxic Hyperactivity and Partial Independence from Hsp70. Journal of Biological Chemistry. 288, 2857-2869

70. Oguchi, Y., Kummer, E., Seyffer, F., Berynskyy, M., Anstett, B., Zahn, R., Wade, R. C., Mogk, A., and Bukau, B. (2012) A tightly regulated molecular toggle controls AAA+ disaggregase. Nature Structural \& Molecular Biology. 19, 1338-1346

71. Nillegoda, N. B., Stank, A., Malinverni, D., Alberts, N., Szlachcic, A., Barducci, A., de Los Rios, P., Wade, R. C., and Bukau, B. (2017) Evolution of an intricate J-protein network driving protein disaggregation in eukaryotes. eLife. 10.7554/eLife. 24560

72. Walters, R. W., Muhlrad, D., Garcia, J., and Parker, R. (2015) Differential effects of Ydj1 and Sis1 on Hsp70-mediated clearance of stress granules in Saccharomyces cerevisiae. RNA (New York, N.Y.). 21, 1660-71

73. Summers, D. W., Wolfe, K. J., Ren, H. Y., and Cyr, D. M. (2013) The type II Hsp40 Sis1 cooperates with Hsp70 and the E3 ligase Ubr1 to promote degradation of terminally misfolded cytosolic protein. PLOS ONE. 8, e52099-

74. Aron, R., Lopez, N., Walter, W., Craig, E. A., and Johnson, J. (2005) In vivo bipartite interaction between the Hsp40 Sis1 and Hsp70 in Saccharomyces cerevisiae. Genetics. 169, 1873

75. Stein, K. C., and True, H. L. (2014) Structural variants of yeast prions show conformer-specific requirements for chaperone activity. Molecular Microbiology. 93, 1156-1171

76. Verma, A. K., Tamadaddi, C., Tak, Y., Lal, S. S., Cole, S. J., Hines, J. K., and Sahi, C. (2019) The expanding world of plant J-domain proteins. Critical Reviews in Plant Sciences. 38, 382-400

77. Konno, T. (2001) Multistep nucleus formation and a separate subunit contribution of the amyloidgenesis of heat-denatured monellin. Protein Science. 10, 2093-2101

78. Mostaert, A. S., Higgins, M. J., Fukuma, T., Rindi, F., and Jarvis, S. P. (2006) Nanoscale mechanical characterisation of amyloid fibrils discovered in a natural adhesive. Journal of biological physics. 32, 393401

79. Mostaert, A. S., Giordani, C., Crockett, R., Karsten, U., Schumann, R., and Jarvis, S. P. (2009) Characterisation of Amyloid Nanostructures in the Natural Adhesive of Unicellular Subaerial Algae. The Journal of Adhesion. 85, 465-483

80. Tang, C.-H., and Wang, C.-S. (2010) Formation and Characterization of Amyloid-like Fibrils from Soy $\beta$-Conglycinin and Glycinin. Journal of Agricultural and Food Chemistry. 58, 11058-11066

81. Ridgley, D. M., Ebanks, K. C., and Barone, J. R. (2011) Peptide Mixtures Can Self-Assemble into Large Amyloid Fibers of Varying Size and Morphology. Biomacromolecules. 12, 3770-3779 
82. Munialo, C. D., Martin, A. H., van der Linden, E., and de Jongh, H. H. J. (2014) Fibril Formation from Pea Protein and Subsequent Gel Formation. Journal of Agricultural and Food Chemistry. 62, 2418-2427

83. Garvey, M., Meehan, S., Gras, S. L., Schirra, H. J., Craik, D. J., van der Weerden, N. L., Anderson, M. A., Gerrard, J. A., and Carver, J. A. (2013) A radish seed antifungal peptide with a high amyloid fibrilforming propensity. Biochimica et Biophysica Acta (BBA) - Proteins and Proteomics. 1834, 1615-1623

84. Gour, S., Kaushik, V., Kumar, V., Bhat, P., Yadav, S. C., and Yadav, J. K. (2016) Antimicrobial peptide (Cn-AMP2) from liquid endosperm of Cocos nucifera forms amyloid-like fibrillar structure. Journal of Peptide Science. 22, 201-207

85. Konno, T., Murata, K., and Nagayama, K. (1999) Amyloid-like aggregates of a plant protein: a case of a sweet-tasting protein, monellin. FEBS Letters. 454, 122-126

86. Villar-Piqué, A., Sabaté, R., Lopera, O., Gibert, J., Torne, J. M., Santos, M., and Ventura, S. (2010) Amyloid-Like Protein Inclusions in Tobacco Transgenic Plants. PLOS ONE. 5, e13625-

87. Chakrabortee, S., Kayatekin, C., Newby, G. A., Mendillo, M. L., Lancaster, A., and Lindquist, S. (2016) Luminidependens (LD) is an Arabidopsis protein with prion behavior. Proceedings of the National Academy of Sciences. 113, 6065

88. Schaefer, M. H., Wanker, E. E., and Andrade-Navarro, M. A. (2012) Evolution and function of CAG/polyglutamine repeats in protein-protein interaction networks. Nucleic Acids Research. 40, 4273-4287

89. Antonets, K. S., and Nizhnikov, A. A. (2017) Predicting Amyloidogenic Proteins in the Proteomes of Plants. International journal of molecular sciences. 18, 2155

90. Letunic, I., and Bork, P. (2017) 20 years of the SMART protein domain annotation resource. Nucleic Acids Research. 46, D493-D496

91. Liu, W., Xie, Y., Ma, J., Luo, X., Nie, P., Zuo, Z., Lahrmann, U., Zhao, Q., Zheng, Y., Zhao, Y., Xue, Y., and Ren, J. (2015) IBS: an illustrator for the presentation and visualization of biological sequences.

Bioinformatics. 31, 3359-3361

92. Arnold, K., Bordoli, L., Kopp, J., and Schwede, T. (2006) The SWISSMODEL workspace: a web-based environment for protein structure homology modelling. Bioinformatics. 22, 195-201

93. Madeira, F., Park, Y. M., Lee, J., Buso, N., Gur, T., Madhusoodanan, N., Basutkar, P., Tivey, A. R. N., Potter, S. C., Finn, R. D., and Lopez, R. (2019) The EMBL-EBI search and sequence analysis tools APIs in 2019. Nucleic acids research. 47, W636-W641

94. Nakagawa, T., Kurose, T., Hino, T., Tanaka, K., Kawamukai, M., Niwa, Y., Toyooka, K., Matsuoka, K., Jinbo, T., and Kimura, T. (2007)

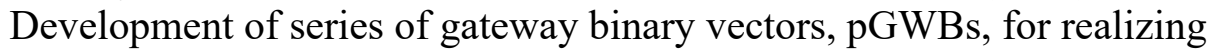
efficient construction of fusion genes for plant transformation. Journal of Bioscience and Bioengineering. 104, 34-41

95. Nakamura, S., Mano, S., Tanaka, Y., Ohnishi, M., Nakamori, C., Araki, M., Niwa, T., Nishimura, M., Kaminaka, H., Nakagawa, T., Sato, Y., and Ishiguro, S. (2010) Gateway binary vectors with the bialaphos resistance 
gene, bar, as a selection marker for plant transformation. Bioscience, Biotechnology and Biochemistry. 74, 1315-1319

96. Sikorski, R. S., and Boeke, J. D. (1991) In vitro mutagenesis and plasmid shuffling: from cloned gene to mutant yeast. in Methods in Enzymology, pp. 302-318, Academic Press, 194, 302-318

97. Yoo, S. D., Cho, Y. H., and Sheen, J. (2007) Arabidopsis mesophyll protoplasts: A versatile cell system for transient gene expression analysis. Nature Protocols. 2, 1565-1572

98. Schneider, C. A., Rasband, W. S., and Eliceiri, K. W. (2012) NIH Image to ImageJ: 25 years of image analysis. Nature Methods. 9, 671675

99. Bustin, S. A., Benes, V., Garson, J. A., Hellemans, J., Huggett, J., Kubista, M., Mueller, R., Nolan, T., Pfaffl, M. W., Shipley, G. L., Vandesompele, J., and Wittwer, C. T. (2009) The MIQE Guidelines: minimum information for publication of quantitative Real-Time PCR experiments. Clinical Chemistry. 55, 611-622

100. Katoh, K., Rozewicki, J., and Yamada, K. D. (2018) MAFFT online service: Multiple sequence alignment, interactive sequence choice and visualization. Briefings in Bioinformatics. 20, 1160-1166

101. Robert, X., and Gouet, P. (2014) Deciphering key features in protein structures with the new ENDscript server. Nucleic Acids Research. 42, W320-W324 
Figures and figure legends:

A

\begin{tabular}{cccccc}
\hline $\begin{array}{c}\text { Standard } \\
\text { name }\end{array}$ & Gene locus & $\begin{array}{c}\text { Identity with } \\
\text { Sis1 }\end{array}$ & $\begin{array}{c}\text { Similarity } \\
\text { with } \\
\text { Sis1 }\end{array}$ & $\begin{array}{c}\text { Length } \\
\text { Molecular } \\
\text { weight }\end{array}$ \\
\hline atDjB1 & AT5G01390 & $39 \%$ & $53.60 \%$ & 335 & 36.97 \\
atDjB4 & AT3G08910 & $38 \%$ & $51.80 \%$ & 323 & 35.79 \\
atDjB3 & AT2G20560 & $38 \%$ & $53.90 \%$ & 337 & 37.11 \\
atDjB10 & AT5G25530 & $38 \%$ & $50.90 \%$ & 347 & 37.94 \\
atDjB2 & AT4G28480 & $38 \%$ & $50.80 \%$ & 348 & 38.19 \\
atDjB5 & AT1G10350 & $37 \%$ & $50.30 \%$ & 348 & 38.76 \\
atDjB6 & AT1G59725 & $34 \%$ & $48.10 \%$ & 331 & 36.61 \\
atDjB17 & AT3G47940 & $33 \%$ & $49.20 \%$ & 350 & 39.03 \\
\hline
\end{tabular}

B

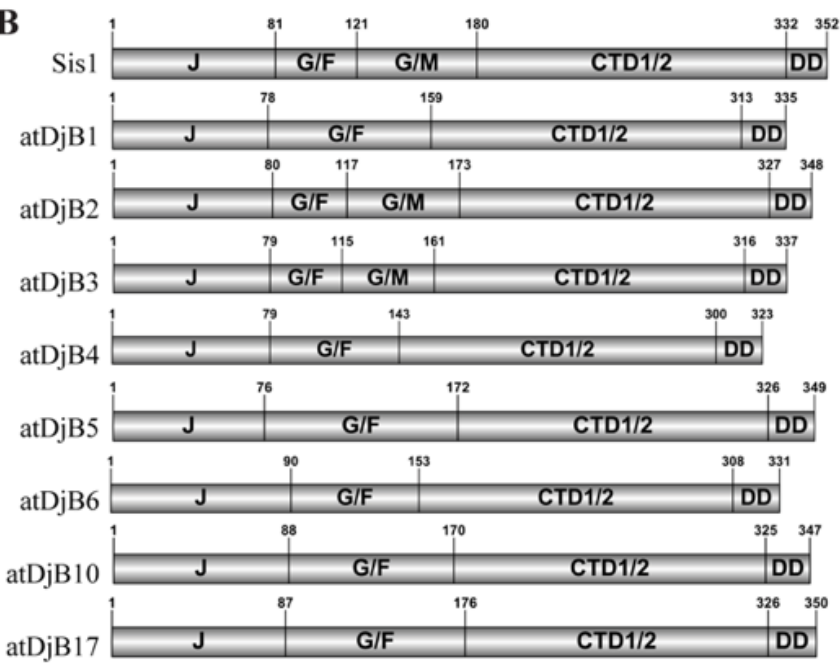

C
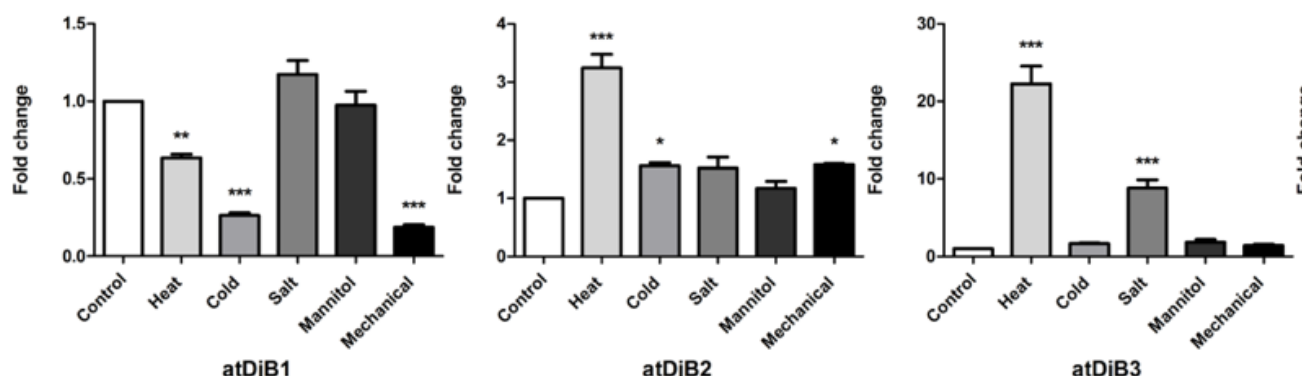

atDjB3

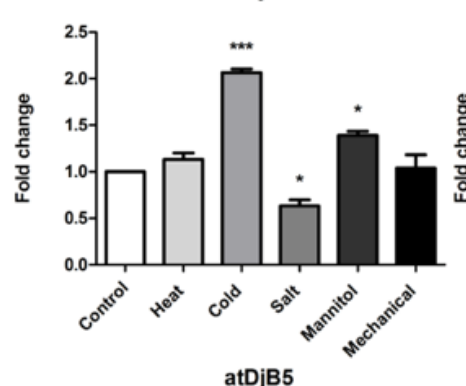

atDjB5

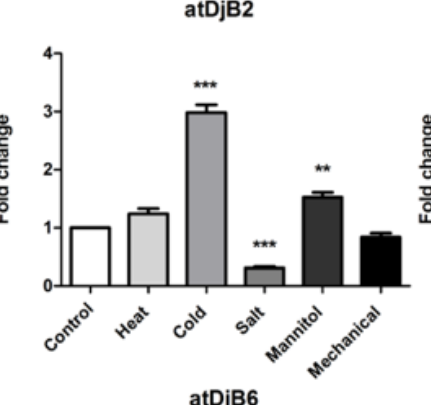

atDjB10

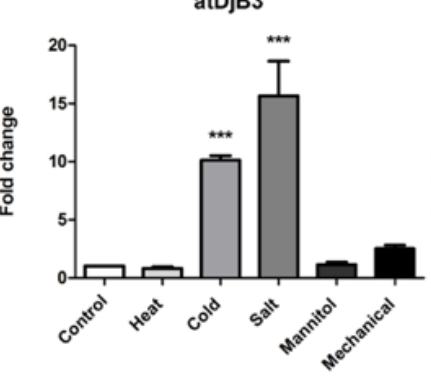

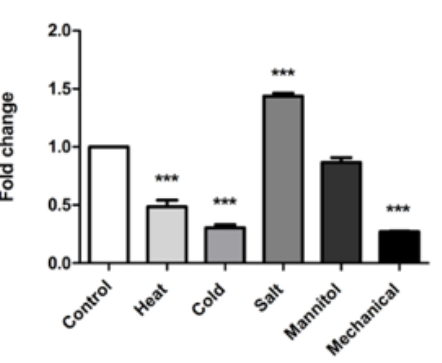

atDjB4

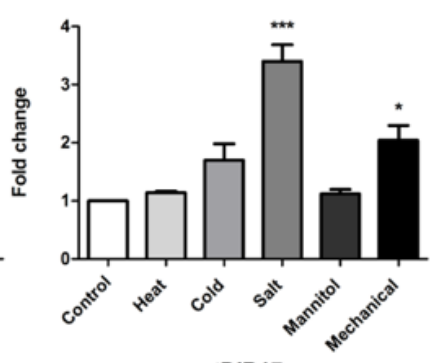

atDjB17

Fig. 1. Protein sequence features of $\boldsymbol{A}$. thaliana atDjBs and their expression profiling. A. Percent identity and similarity between full-length protein sequences of $A$. thaliana atDjBs and Sis1. B. Domain organization of $A$. thaliana atDjBs. J-domain (J), glycine phenylalanine-rich region (GF), glycine methionine-rich region (GM), C-terminal peptide-binding domains I and II (CTD1/2), dimerization domain (DD). The domain structures were drawn to scale, and amino-acid numbers were shown over each domain. C. Differential expression pattern of atDjBs under abiotic stress conditions. qRT-PCR analysis showing relative expression of atDjBs examined in the WT under control and different abiotic stress conditions: Heat $\left(37^{\circ} \mathrm{C}\right.$ for $\left.60 \mathrm{~min}\right)$, Cold $\left(4^{\circ} \mathrm{C}\right.$ for $\left.24 \mathrm{~h}\right)$, Salt $(150 \mathrm{mM} \mathrm{NaCl}$ for $24 \mathrm{~h})$, Mannitol (150mM Mannitol for 24h), or Mechanical (mechanical injury, 60min). Gene expression levels were normalized in stressed samples with the respective genes in unstressed samples, followed by normalization with the expression level of $A C T I N$ (AT3G1870) gene. Significant transcript level differences were indicated by asterisks $(* * * P<0.0001, * * P<0.001, * P<0.01)$ analyzed using 2 wayANOVA with Dunnett's multiple comparison test. Data are mean \pm SD of three biological and technical replicates. 

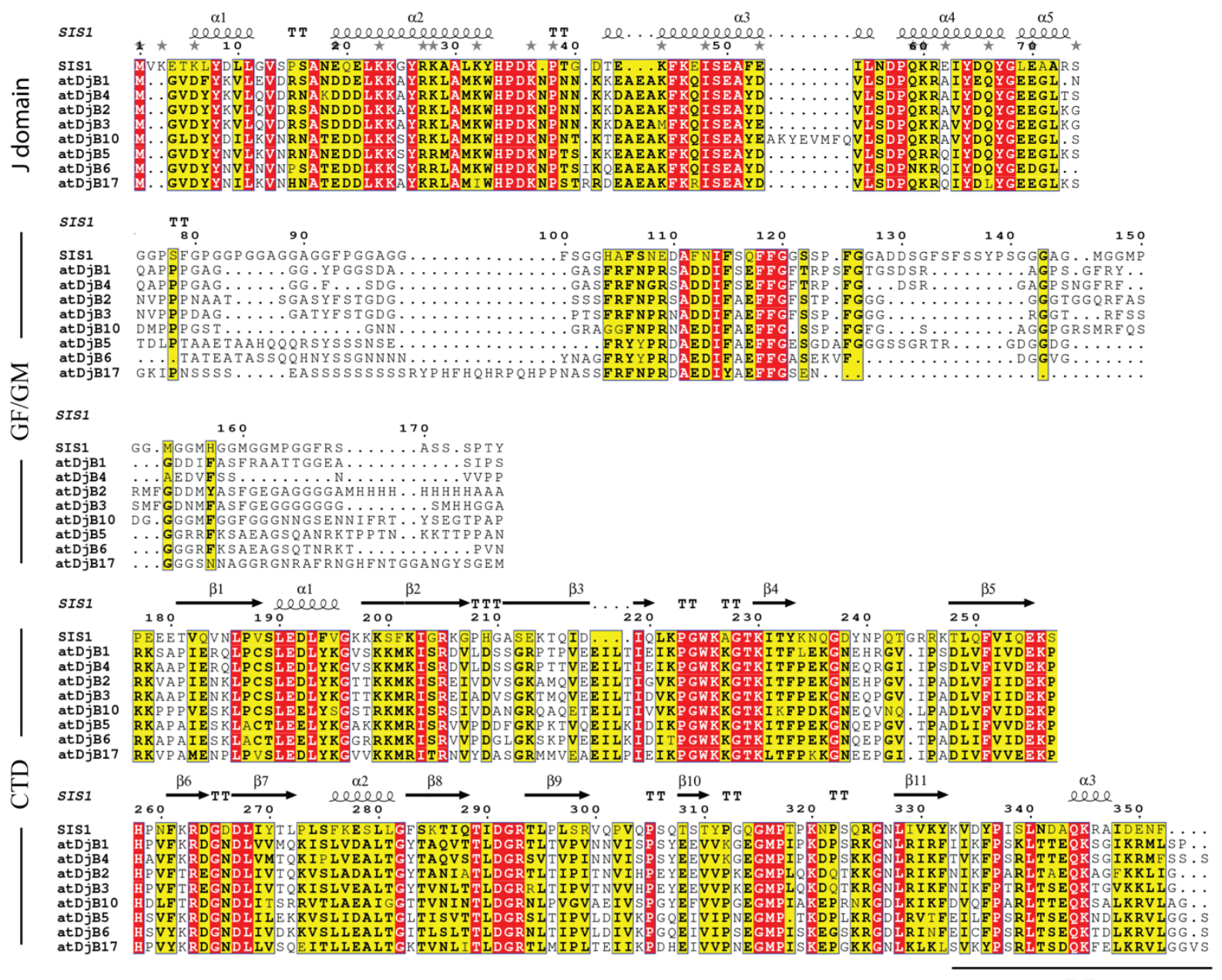

DD

Fig. S1. Sequence alignment of Sis1 and atDjBs. Homology comparison of amino acid sequences of Sis 1 and its $A$. Thaliana atDjBs orthologs. The multiple sequence alignment was carried out using MAFFT ver.7 (100), followed by ESPript 3.0 (101). Domains are indicated. The secondary structure element for J-domain (PDB: 4RWU) and CTD (PDB: 1C3G) of Sis1 are given above their corresponding sequences. The conserved residues are indicated by the default colouring scheme of the ESPript program. Arrow, spring, TT and TTT above the sequences represent $\beta$-strand, helical, strict $\beta$ turn and strict $\alpha$-turn conformations, respectively. 
A

\begin{tabular}{cccc}
\hline $\begin{array}{c}\text { Standard } \\
\text { name }\end{array}$ & Gene locus & $\begin{array}{c}\text { Accession } \\
\text { number }\end{array}$ & E- value \\
\hline atDjB1 & AT5G01390 & NP_195759.1 & $1.00 \mathrm{E}-61$ \\
atDjB2 & AT2G28480 & NP_194577.1 & $4.00 \mathrm{E}-52$ \\
atDjB3 & AT2G20560 & NP_179646.1 & $7.00 \mathrm{E}-60$ \\
atDjB4 & AT3G01890 & NP_187503.1 & $8.00 \mathrm{E}-58$ \\
atDjB5 & AT1G10350 & NP_172506.1 & $1.00 \mathrm{E}-54$ \\
atDjB6 & AT1G59725 & NP_176181.1 & $2.00 \mathrm{E}-52$ \\
atDjB10 & AT5G25530 & NP_197935.1 & $6.00 \mathrm{E}-56$ \\
atDjB17 & AT3G47940 & NP_190377.1 & $7.00 \mathrm{E}-52$ \\
\hline
\end{tabular}

B
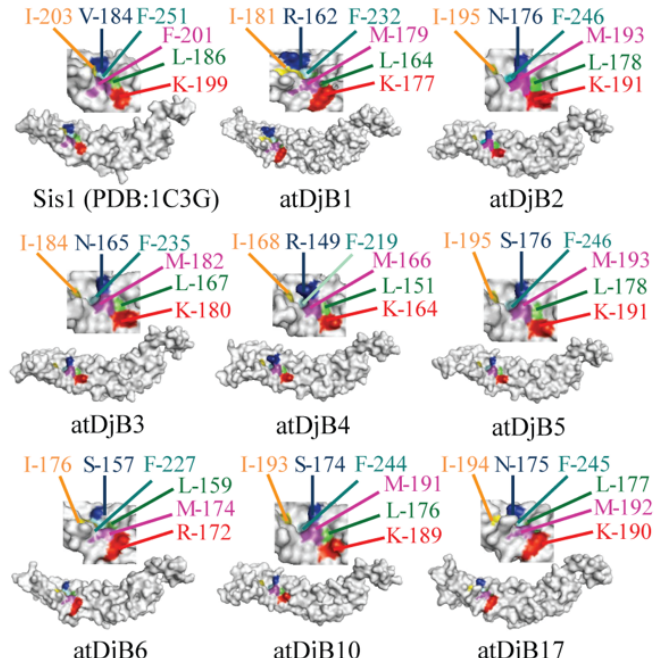

$\mathrm{C}$

SIS1 EETVQVNLPV SLEDLFVGKK KSFKIGRKGP HGASEKTQID $\ldots \ldots$ IQLKPG $\ldots \ldots \ldots$. . . . RRKTLQFVIQ atDjB1 SAPIERQLPC SLEDLYKGVS KKMKISRDVL DSSGRPTPVE EILTIEIKPG $\ldots \ldots \ldots$ atDjB2 VAPIENKLPC SLEDLYKGTT KKMKISREIV DVSGKAMQVE EILTIGVKPG $\ldots \ldots \ldots$ atDjB3 AAPIENKLPC SLEDLYKGTT KKMRISREIA DVSGKTMQVE EILTIDVKPG $\ldots \ldots \ldots$ atDjB4 AAPIERQLPC SLEDLYKGVS KKMKISRDVL DSSGRPTTVE EILTIEIKPG $\ldots \ldots \ldots$ atDjB5 APAIESKLAC TLEELYKGAK KKMRISRVVP DDFGKPKTVQ EILKIDIKPG $\ldots \ldots \ldots \ldots$. . . . TPADLIFVVD

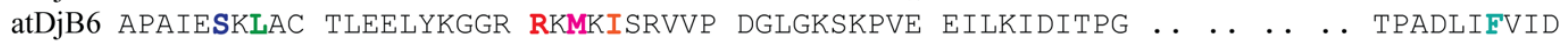
atDjB10 PPPVESKLPC SLEELYSGST RKMKISRSIV DANGRQAQET EILTIVVKPG $\ldots \ldots \ldots \ldots$. atDjB17 VPAMENPLPV SLEDLYKGVV KKMRITRNVY DASGRMMVEA EILPIEIKPG $\ldots \ldots \ldots$

\section{Fig. S2. Conserved features among $A$. thaliana atDjBs sequence}

A.E-values and NCBI accession number of $A$. thaliana atDjBs. B. Peptide-binding clefts for Sis1 orthologs. atDjB1, atDjB2, atDjB3, atDjB4, atDjB5, atDjB6, atDjB10 and atDjB17 have peptidebinding clefts similar to Sis1. Surface-filled models of C-terminal region of Sis1 (PDB:1C3G), Sis1 (residues 180 to 352) was made using SWISS MODELER homology-modelling server. Models of peptide-binding clefts of atDjB1 (residues 159 to 335), atDjB2 (residues 173 to 348), atDjB3 (residues 161 to 337), atDjB4 (residues 143 to 323), atDjB5 (residues 172 to 349), atDjB6 (residues 153 to 331), atDjB10 (residues 170 to 347 ) and atDjB17 (residues 176 to 350 ) $\mathrm{J}$ proteins, based on the crystal structure of Sis1.C. Sequence alignment represents the conserved amino acid residues forming the peptide-binding cleft. Conserved amino acids highlighted with colours. 


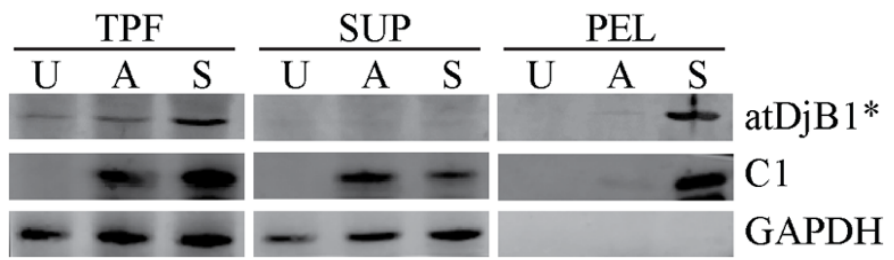

Fig. 2. atDjBs are heat-inducible and associate with heat-induced protein aggregates. Total protein lysate was isolated from Arabidopsis seedlings that were unstressed (U), acclimatized at $38^{\circ} \mathrm{C}$ for 90 min followed by $120 \mathrm{~min}$ at $22^{\circ} \mathrm{C}(\mathrm{A})$, and heat stressed for $180 \mathrm{~min}$ at $45^{\circ} \mathrm{C}$ with preconditioning (S). Lysates were then fractionated by centrifugation into supernatant (SUP) and pellet (PEL) fractions, and resolved along with total protein fraction (TPF) on 15\% SDS-PAGE and electroblotted. Blots were probed with anti-atDjB1, anti-sHsp antibodies and anti-GAPDH as a loading control. Asterisk $\left(^{*}\right)$ represent the polyclonal antibody against atDjB1 that cross reacts with atDjB2, atDjB3 and atDjB4.

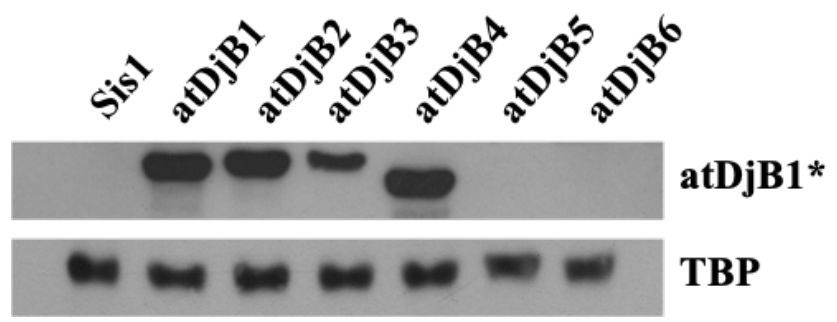

Fig. S3. Characterization of a polyclonal antibody against atDjBs. Equal amounts of total cell lysate prepared from sis $1 \Delta$ cells harboring plasmids expressing Sis1 or atDjB1-6 were resolved on SDSPAGE, electroblotted, and probed with anti-atDjB1 antibody. Anti-TBP1 antibody was used as loading control. Asterisk $(*)$ represent polyclonal antibody against atDjB1 that cross reacts with atDjB2, atDjB3 and atDjB4. 


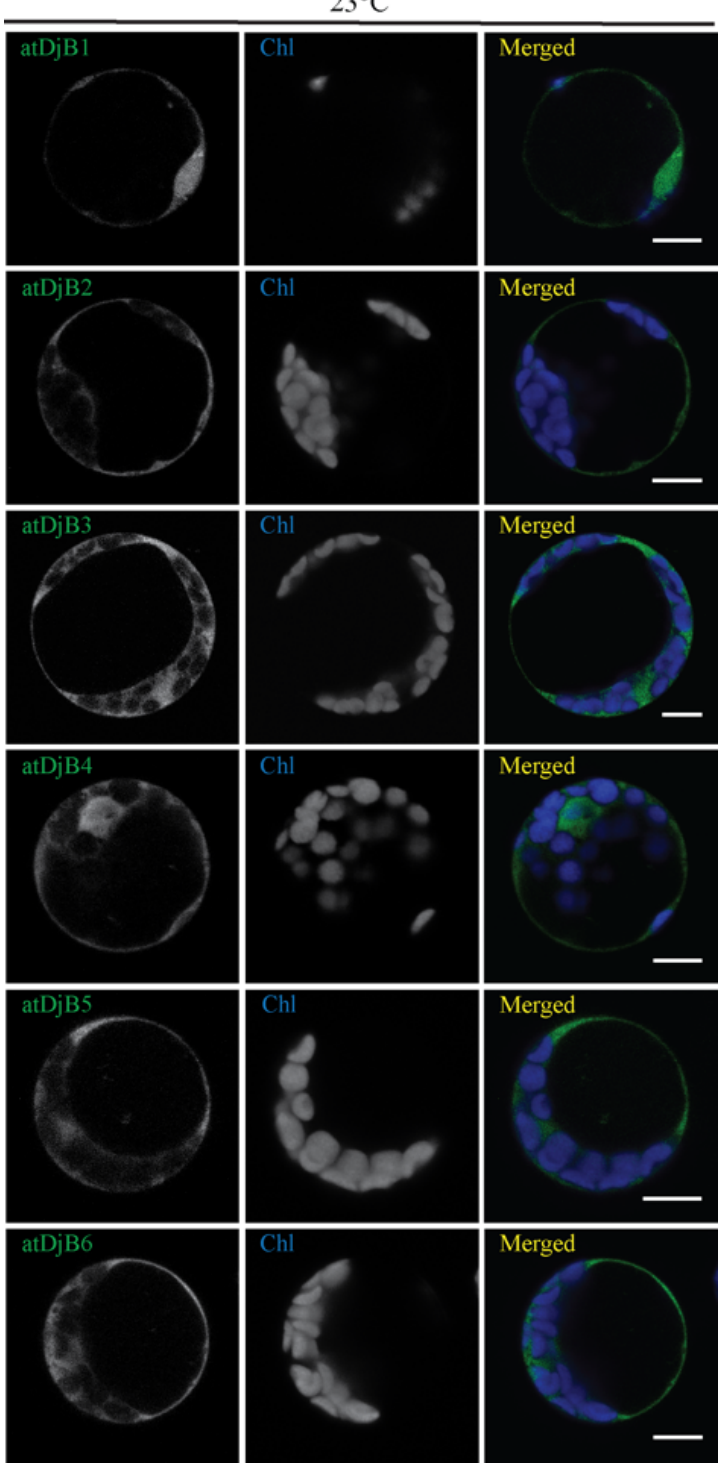

Fig. 3. Subcellular localization of atDjBs in A. thaliana protoplasts. A. thaliana leaf protoplasts were transfected with the vectors expressingatDjB1-GFP, atDjB2-GFP, atDjB3-GFP, atDjB4-GFP, atDjB5$\mathrm{GFP}$, and atDjB6-GFP fusion proteins under control conditions $\left(23^{\circ} \mathrm{C}\right)$. The green signals indicate GFP, and the blue signals indicate autofluorescence of chlorophyll. GFP-mediated fluorescence, derived from individual atDjBs and chlorophyll autofluorescence were visualized using FITC $(495 \mathrm{~nm} / 519 \mathrm{~nm})$ and Cy5 $(678 \mathrm{~nm} / 694 \mathrm{~nm})$ filter set. All images are single slice of confocal sections taken with living protoplast $12 \mathrm{~h}$ after transfection. Scale bar, $10 \mu \mathrm{m}$. 
A
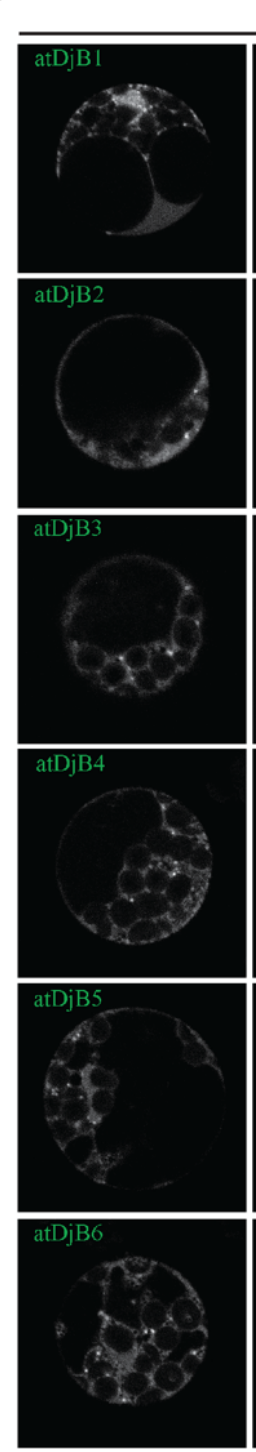

$38^{\circ} \mathrm{C}$
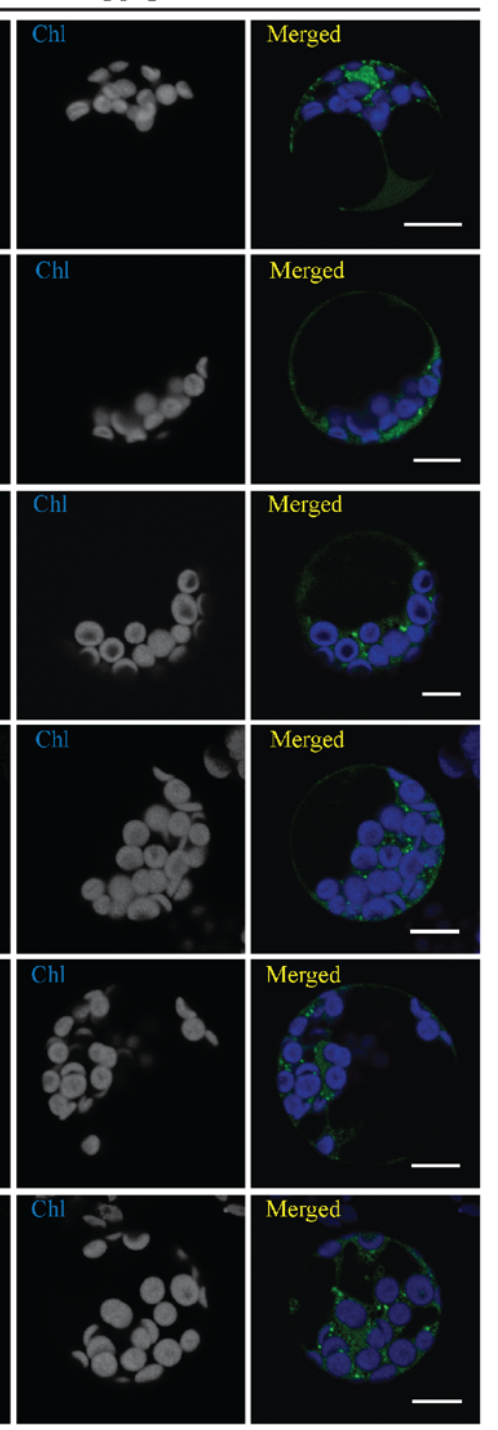

B

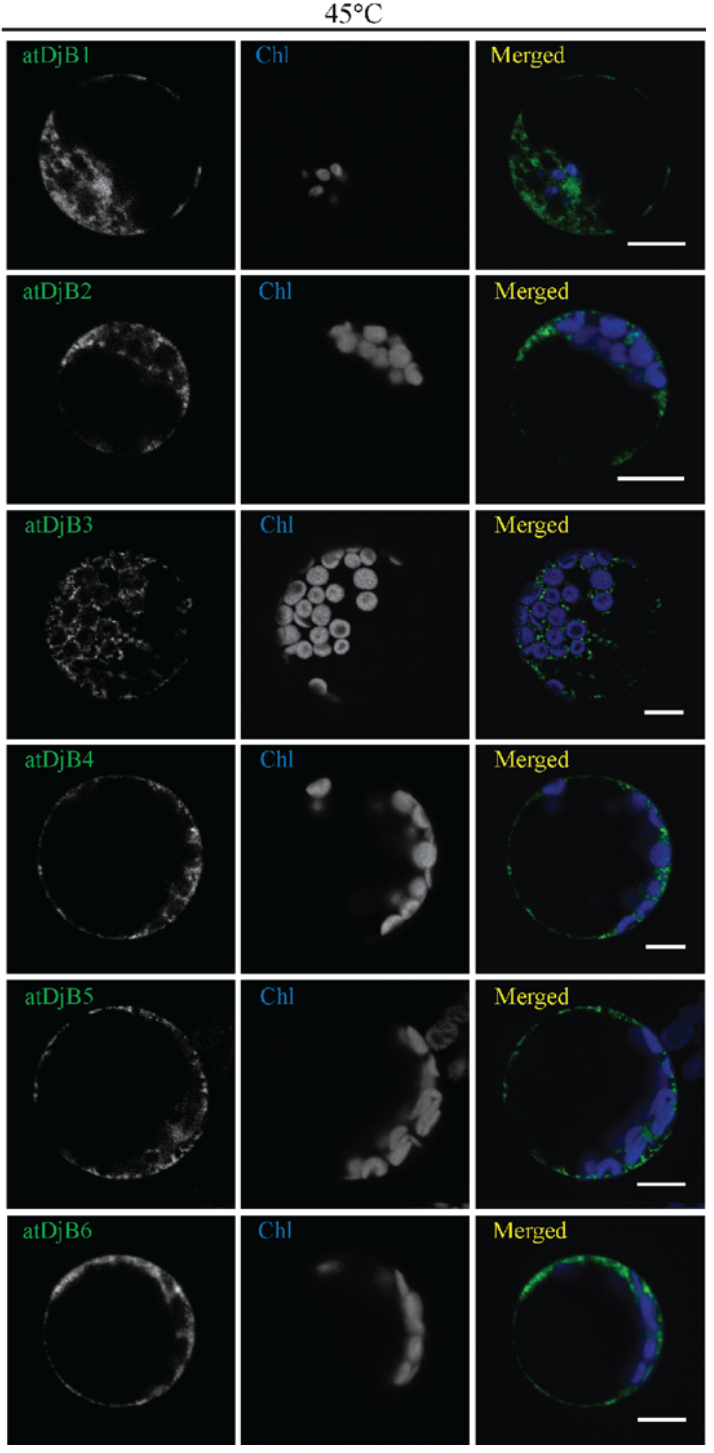

Fig. S4.Heat stress induces re-localization of atDjBs to multiple cytoplasmic foci in $A$. thaliana protoplast. A and B.A. thaliana protoplasts transiently expressing individual atDjB-GFP constructs were pre-conditioned at $38^{\circ} \mathrm{C}$ for $30 \mathrm{~min}(\mathrm{~A})$ or at $45^{\circ} \mathrm{C}$ for $15 \mathrm{~min}(\mathrm{~B})$ before taking the images. The green signals indicate GFP, and the blue signals indicate autofluorescence of chlorophyll. GFP mediated fluorescence, derived from individual atDjBs and chlorophyll autofluorescence were visualized using FITC $(495 \mathrm{~mm} / 519 \mathrm{~mm})$ and Cy5 $(678 \mathrm{~mm} / 694 \mathrm{~mm})$ filter set. All images are single slice of confocal sections taken with living protoplast immediately after the above-mentioned stress treatments. Scale bar, $10 \mu \mathrm{m}$. 
A
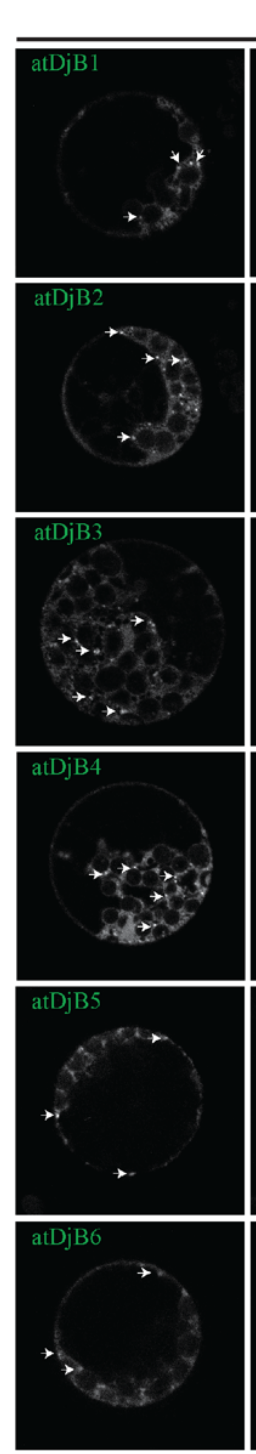

$38^{\circ} \mathrm{C}$
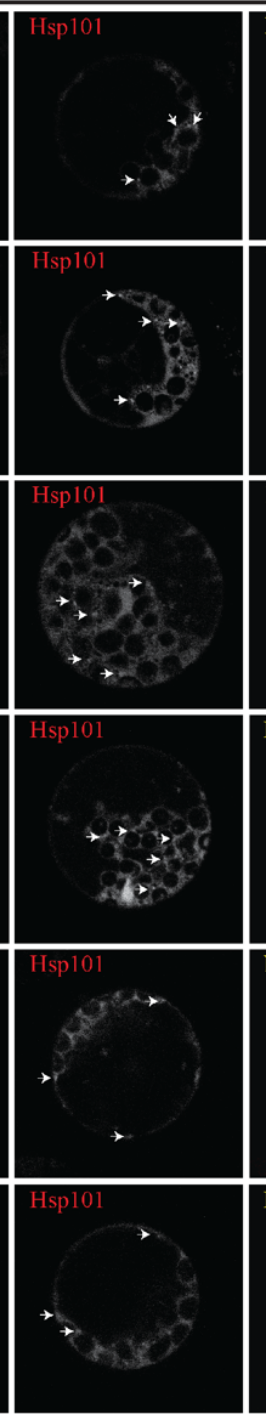

B

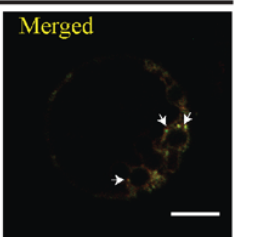

Merged
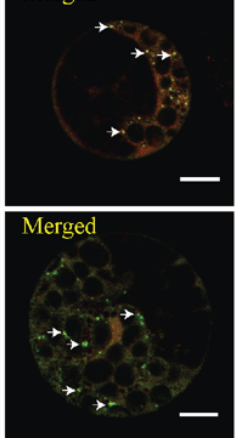

Merged
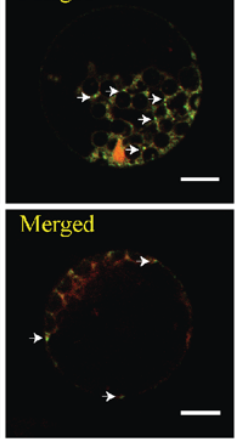

Merged

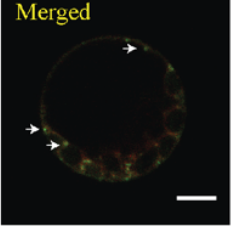

atDjB-Hsp101 $38^{\circ} \mathrm{C}$

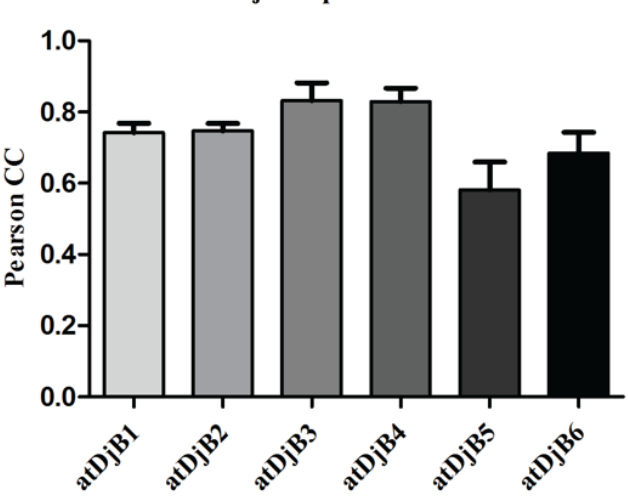

Fig. 4. Heat stress induced multiple cytoplasmic foci of atDjBs colocalize to Hsp101 foci in $A$. thaliana protoplast. A. Protoplast of $A$. thaliana transiently expressing individual atDjB-GFP constructs and Hsp101-RFP were preconditioned at $38^{\circ} \mathrm{C}$ for $30 \mathrm{~min}$. Green indicates GFP, red indicates RFP, and blue indicates the autofluorescence of chlorophyll. GFP-mediated fluorescence, derived from individual atDjBs, RFP-mediated fluorescence derived from Hsp101, and chlorophyll autofluorescence were visualized using FITC $(495 \mathrm{~nm} / 519 \mathrm{~nm})$, m-RFP $(572 \mathrm{~nm} / 606 \mathrm{~nm})$ and Cy5 $(678 \mathrm{~nm} / 694 \mathrm{~nm})$ filter set. All images are single slice of confocal sections taken with living protoplast immediately after the above mentioned stress treatment. Scale bar, $10 \mu \mathrm{m}$. B. Quantification of colocalization of atDjBs (GFP signal) with Hsp101 (RFP-signal) by Pearson's correlation coefficient, each bar represents the average correlation coefficient of $( \pm \mathrm{SD})$ minimum five different protoplasts. Arrow $(\rightarrow)$ represent the cytoplasmic foci for the individual atDjB's. 
A

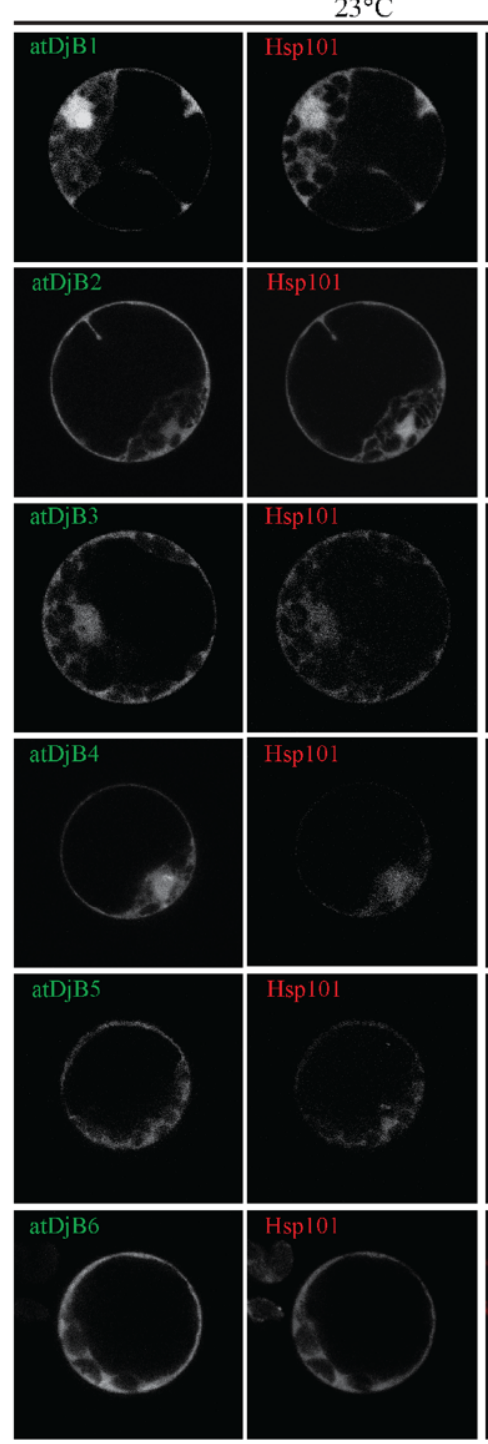

B
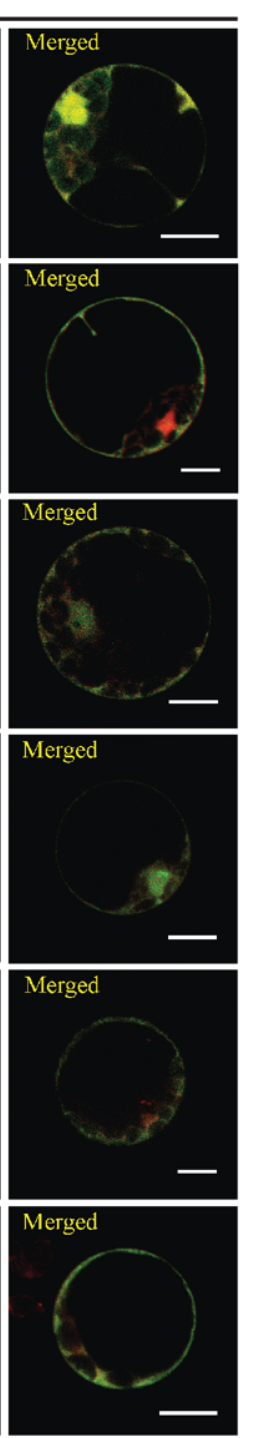

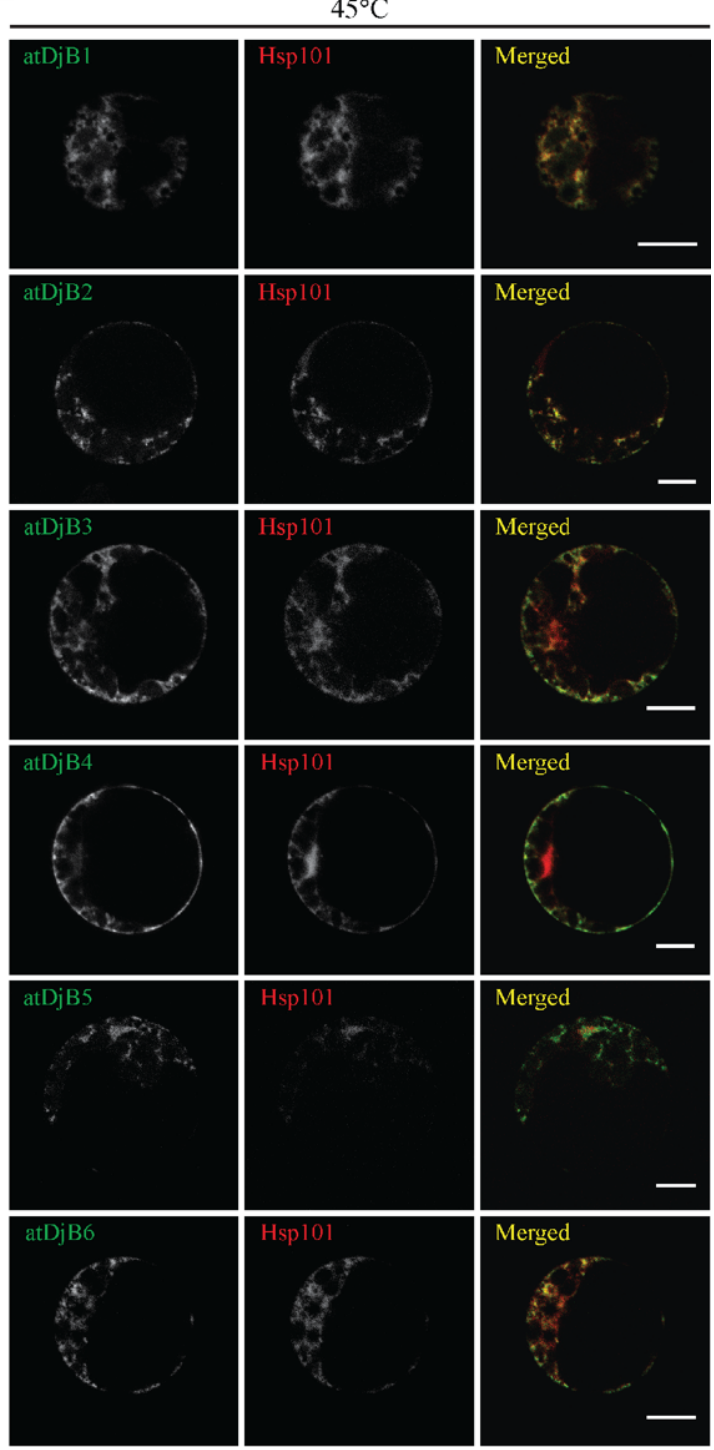

Fig. S5. atDjBs colocalize with Hsp101 in A. thaliana protoplast. A and B. A. thaliana protoplasts transiently expressing individual atDjB-GFP constructs and Hsp101-RFP were visualized at $23^{\circ} \mathrm{C}(\mathrm{A})$ or after $45^{\circ} \mathrm{C}$ for $15 \mathrm{~min}$ (B) heat stress treatment. Green indicates GFP, red indicates RFP, and blue indicates the autofluorescence of chlorophyll. GFP-mediated fluorescence, derived from individual atDjBs, RFP-mediated fluorescence derived from Hsp101, and chlorophyll autofluorescence were visualized using FITC $(495 \mathrm{~nm} / 519 \mathrm{~nm})$, m-RFP $(572 \mathrm{~nm} / 606 \mathrm{~nm})$ and Cy5 $(678 \mathrm{~nm} / 694 \mathrm{~nm})$ filter set. All images are single slice of confocal sections taken with living protoplast immediately after the above mentioned temperature conditions. Scale bar, $10 \mu \mathrm{m}$. 


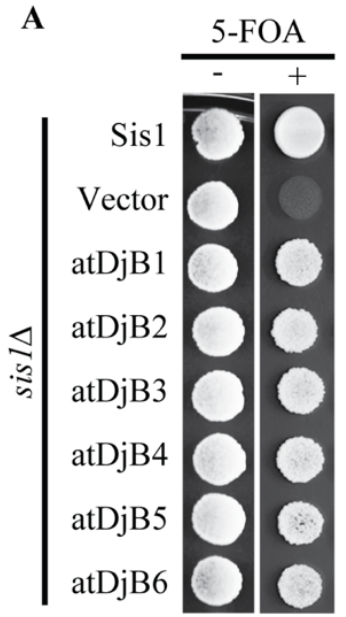

$30^{\circ} \mathrm{C}$

\section{B}

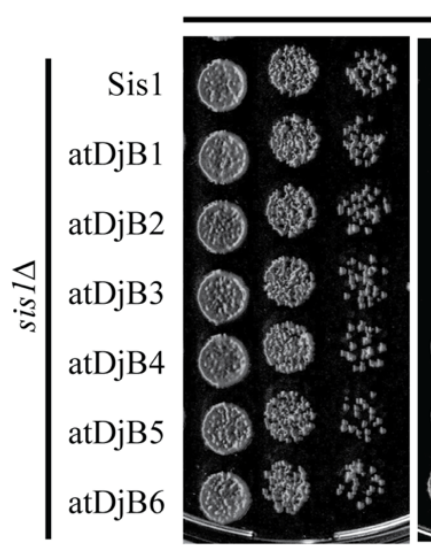

$23^{\circ} \mathrm{C}$
YPD

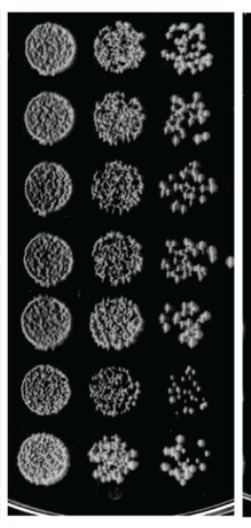

$30^{\circ} \mathrm{C}$

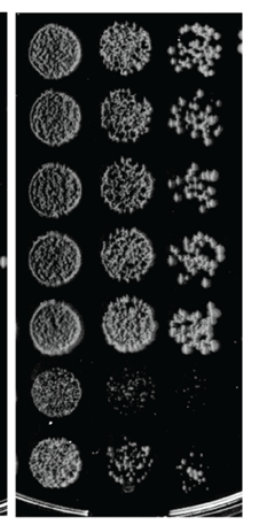

$34^{\circ} \mathrm{C}$

C

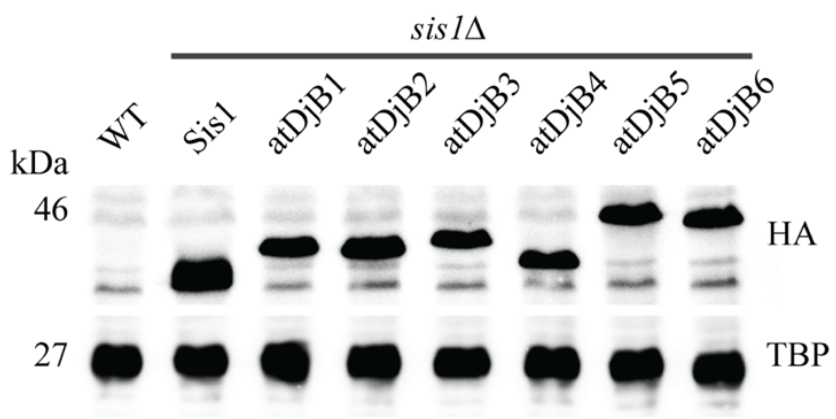

Fig. 5. atDjB1-6 rescue the essential functions of Sis1 in $S$. cerevisiae. A. Equal volume of ten-fold serial dilutions of sis1 1 [URA3-SIS1] cells harboring empty pRS413 plasmid (vector) or pRS413 expressing Sis1 or atDjB1-6 were spotted on media with (+) or without (-) 5-fluoroorotic acid (5-FOA) and incubated at $30^{\circ} \mathrm{C}$ for 3 days. B. Equal volume of ten-fold serial dilutions of sis $1 \Delta$ cells harboring pRS413-Sis1 (Sis1) or pRS413 expressing atDjB1-6 were spotted on YPD plates and incubated at indicated temperatures for 3 days. C. Equal amounts of total cell lysate prepared from sis $1 \Delta$ cells harboring plasmids expressing HA-tagged constructs of Sis1 or atDjB1-6 were resolved on SDS-PAGE, electroblotted, and probed with anti-HA antibody. Anti-TBP1 antibody was used as loading control. WT cells were included as negative control. 
A

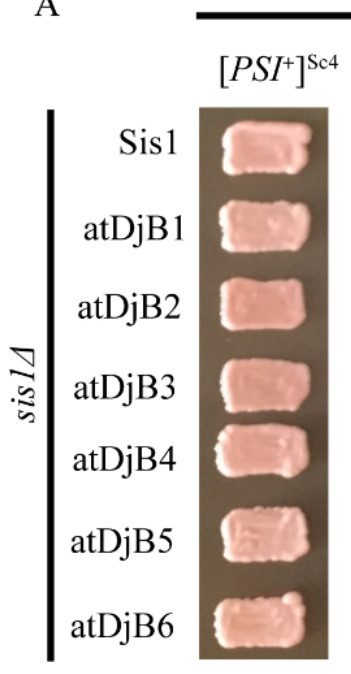

W303

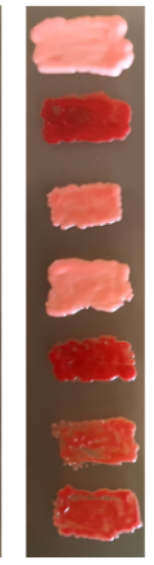

B

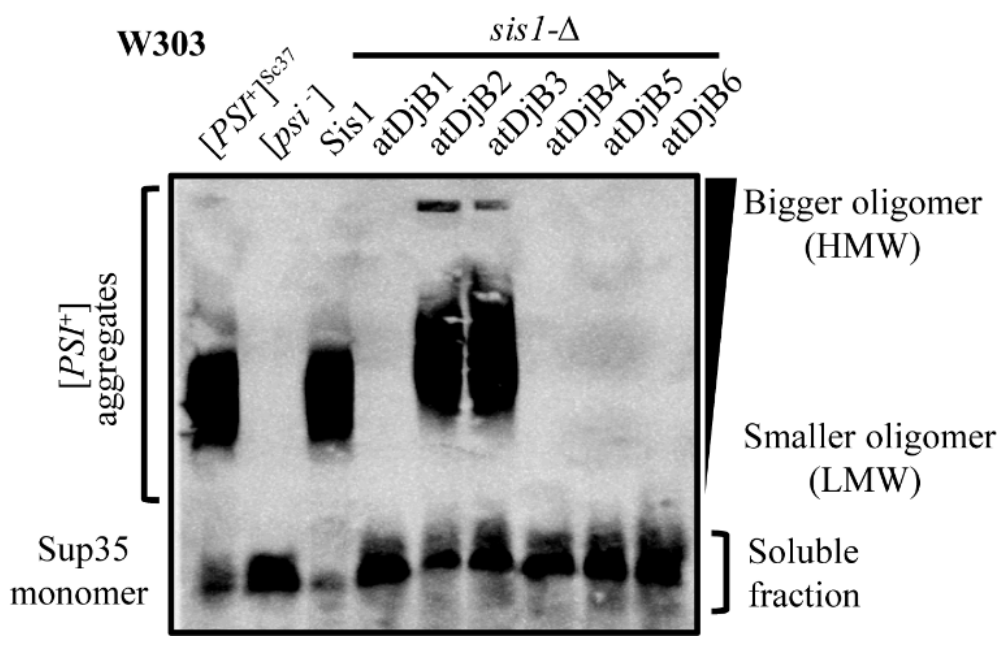

Fig. 6.atDjBs all support strong $\left[P S I^{+}\right]$but differentially maintain weak $\left[\mathrm{PSI}^{+}\right]$variants. A. $\left[P S I^{+}\right]^{\mathrm{Sc} 4},\left[P S I^{+}\right]^{\mathrm{Sc} 37},\left[P S I^{+}\right]^{\mathrm{VH}}$, and $\left[P S I^{+}\right]^{\mathrm{VL}}$ sis $1 \Delta[U R A 3-S I S I]$ cells were transformed with plasmid (pRS414) expressing Sis1 or atDjB1-6 and subjected to plasmid shuffling on 5-fluorooratic acid (5FOA). Cells after plasmid shuffling were assayed for $\left[\mathrm{PSI}^{+}\right]$maintenance by colony color on YPD medium. Color phenotype assays are shown for representative transformants $(n \geq 10)$ including parental strain for comparison. B. The maintenance of $\left[\mathrm{PSI}^{+}\right]^{\mathrm{Sc} 37}$ was further confirmed by semi-denaturing detergent agarose gel electrophoresis (SDDAGE). Equal amount of cell lysate prepared from shuffled strains were resolved by SDDAGE, electroblotted, and probed with anti-Sup35 antibody. $\left[\mathrm{PSI}^{+}\right]^{\mathrm{Sc} 37}$ and GdnHCl-treated [ $p s i]$ parent cells were included for comparison. 


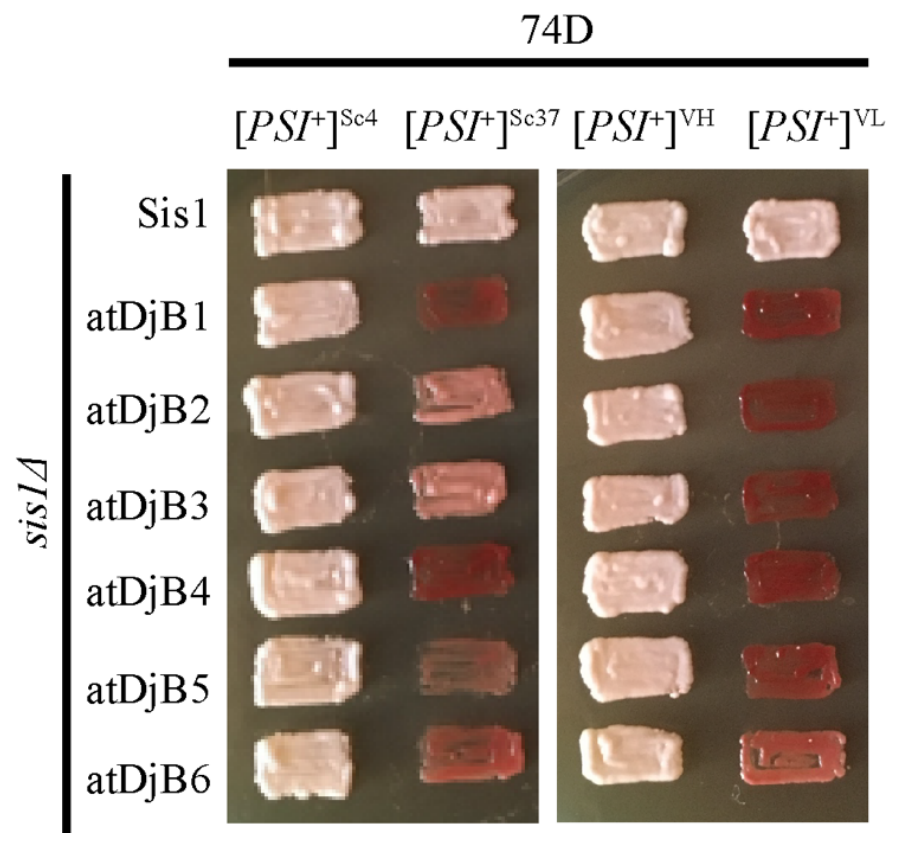

Fig. S6.atDjB $\left[P S I^{+}\right]$maintenance patterns are indistinguishable between the W303 and 74D-694 yeast genetic backgrounds. $\left[P S I^{+}\right]^{\mathrm{Sc} 4},\left[P S I^{+}\right]^{\mathrm{Sc} 37},\left[P S I^{+}\right]^{\mathrm{VH}}$, and $\left[P S I^{+}\right]^{\mathrm{VL}}$ sis $1 \Delta[U R A 3-S I S 1]$ cells were transformed with plasmid (pRS414) expressing Sis1 or atDjB1-6 and subjected to plasmid shuffling on 5-fluorooratic acid (5-FOA). Cells after plasmid shuffling were assayed for $\left[\mathrm{PSI}^{+}\right]$maintenance by colony color on YPD media. Color phenotype assays are shown for representative transformants $(\mathrm{n} \geq$ $10)$. 
A

$$
\left[P S I^{+}\right]^{\mathrm{Sc} 4}
$$

$\left[P S I^{+}\right]^{\mathrm{VH}}$

Initial $\uparrow$ Hsp 104
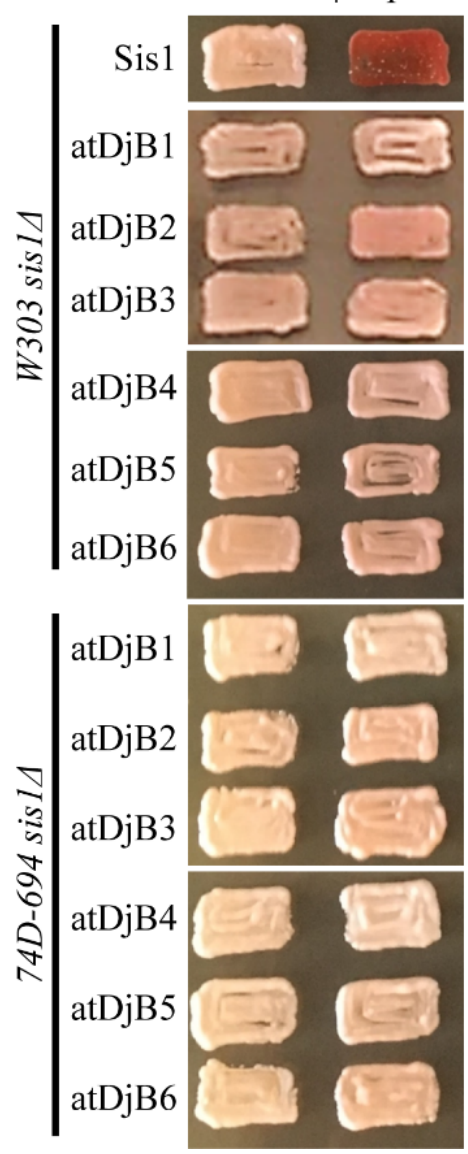

B
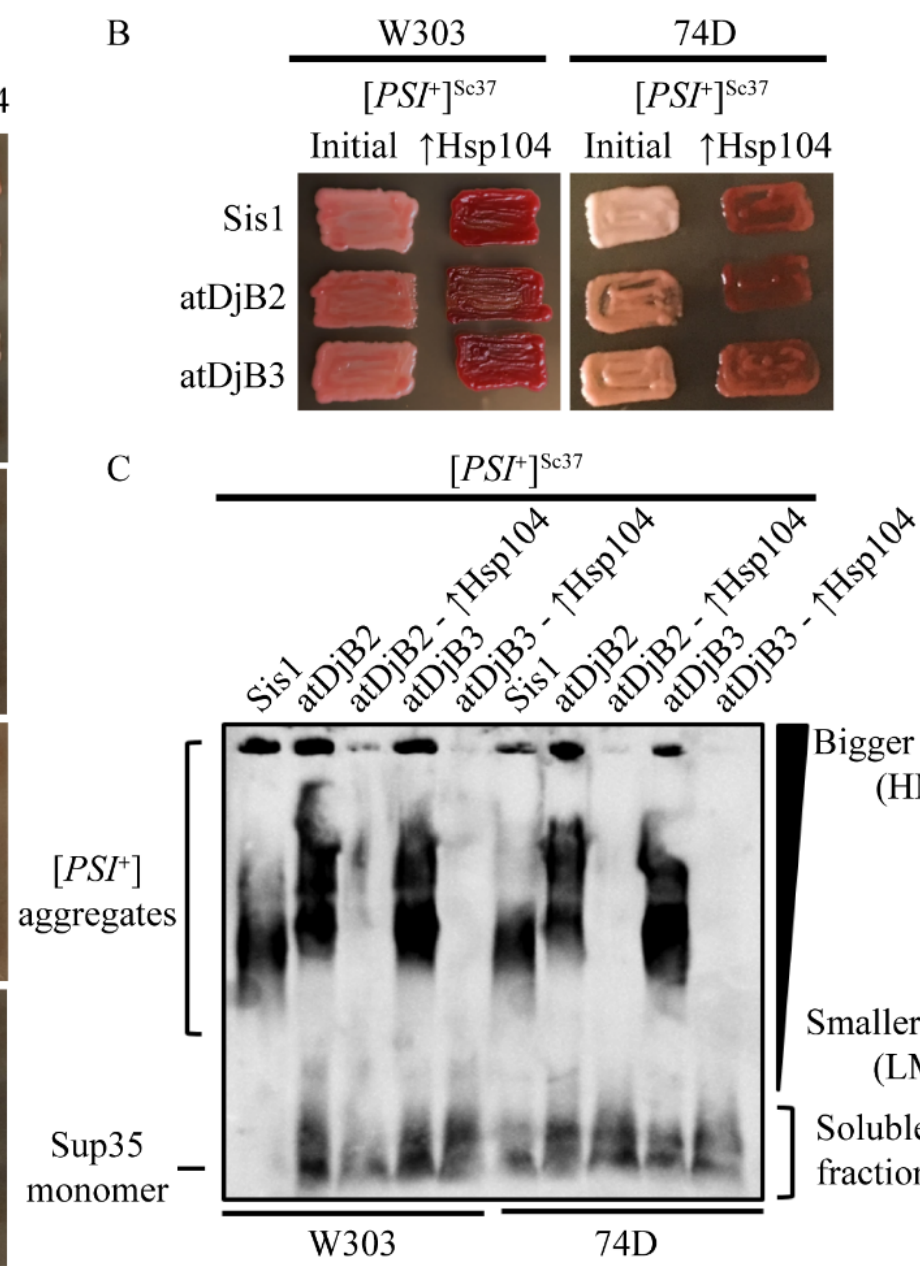

Bigger oligomer (HMW)

Smaller oligomer

(LMW)

Soluble fraction

Fig. 7. JDP requirements for Hsp104-mediated elimination of $\left[P S I^{+}\right]$are prion variant dependent. A. $\left[P S I^{+}\right]^{\mathrm{Sc} 4}$ and $\left[P S I^{+}\right]^{\mathrm{VH}}$ in $\mathrm{W} 303$ or $74 \mathrm{D}-694$ sis $1 \Delta$ shuffled strains expressing Sis 1 or atDjB1-6 were transformed with a plasmid overexpressing Hsp104 (pRS426-GPD-HSP104). Cells from individual transformations were assayed for $\left[\mathrm{PSI}^{+}\right]$curing by colony color on YPD media. Color phenotype assays are shown for representative transformants $(\mathrm{n} \geq 10)$.B. Same as panel A, but cells have $\left[\mathrm{PSI}^{+}\right]^{\mathrm{Sc} 37}$ and express Sis1, atDjB2, or atDjB3. C. $\left[P S I^{+}\right]$-status of cells shown in $\mathrm{B}$ is confirmed by semi-denaturing detergent agarose gel electrophoresis (SDDAGE). Equal amount of cell lysate prepared from shuffled strains from panel B, were resolved by SDDAGE, electroblotted, and probed with anti-Sup35 antibody. 
A

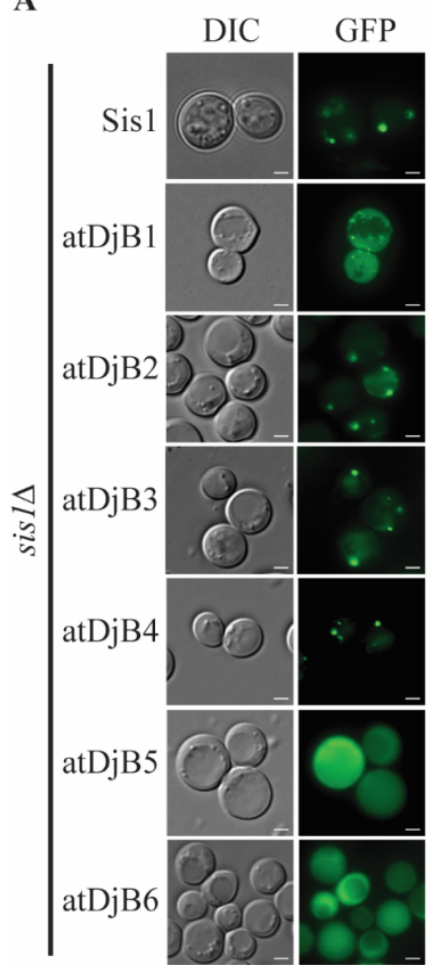

B

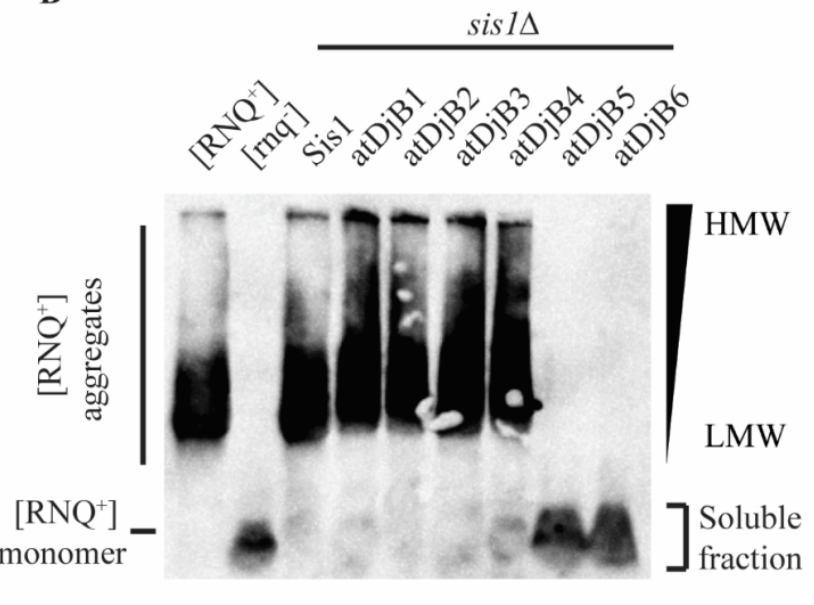

Fig. 8. Maintenance of $\left[R \boldsymbol{N} \boldsymbol{Q}^{+}\right]$by atDjBs. A. $\left[R N Q^{+}\right]$sis $1 \Delta[U R A 3-S I S 1]$ cells were transformed with plasmid (pRS414) expressing Sis1 or atDjB1-6, subjected to plasmid shuffling on 5-fluorooratic acid (5-FOA), and then transformed with a Rnq1-GFP reporter plasmid (pRS413-TEF-RNQ1-GFP) followed by fluorescence microscopy analysis. Scale bar, $2 \mu \mathrm{m}$. B. Equal amounts of cell lysate prepared from shuffled strains from panel $\mathbf{A}$ were resolved on semi-denaturing detergent agarose gel electrophoresis (SDDAGE), electroblotted, and probed with anti-Rnq1 antibody. Control $\left[R N Q^{+}\right]$and GdnHCl-treated $\left[r n q^{-}\right]$parent cells were included for comparison. 


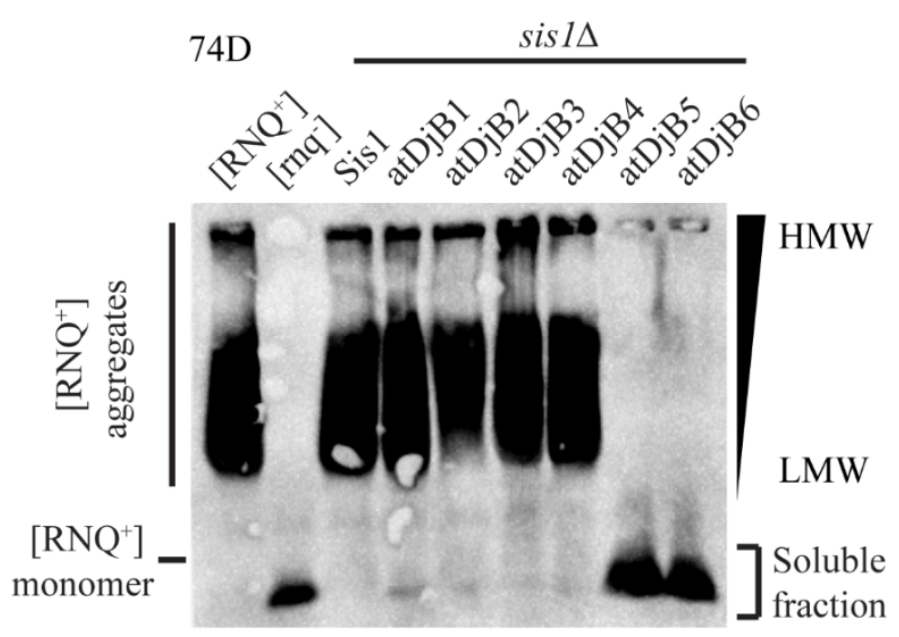

Fig. S7.atDjB $\left[R N Q^{+}\right]$prion maintenance is indistinguishable between $\mathrm{W} 303$ and $74 \mathrm{D}-694$ yeast genetic backgrounds. $\left[R N Q^{+}\right]$sis $1 \Delta$ [URA3-SISI] cells of the 74D-694 background were transformed with plasmid (pRS414) expressing Sis1 or atDjB1-6 and subjected to plasmid shuffling on 5fluorooratic acid (5-FOA). Equal amounts of cell lysate were resolved on semi-denaturing detergent agarose gel electrophoresis (SDDAGE), electroblotted, and probed with anti-Rnq1 antibody. Control $\left[R N Q^{+}\right]$and $\mathrm{GdnHCl}$-treated $\left[r n q^{-}\right]$parent cells were included for comparison. 
A

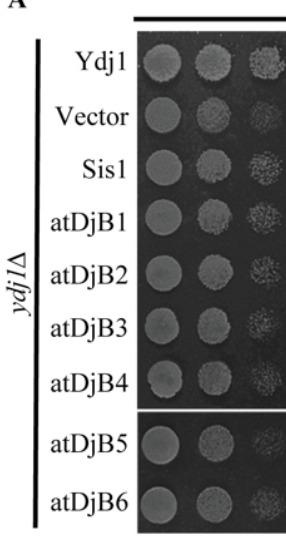

$23^{\circ} \mathrm{C}$
YPD

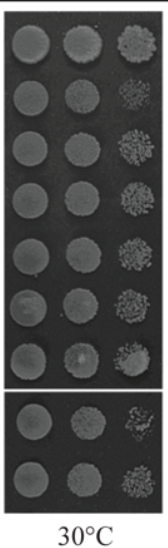

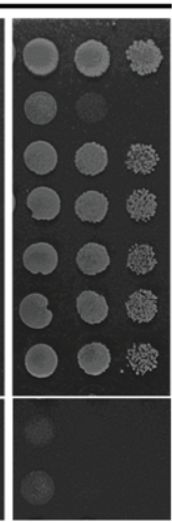

$34^{\circ} \mathrm{C}$
B

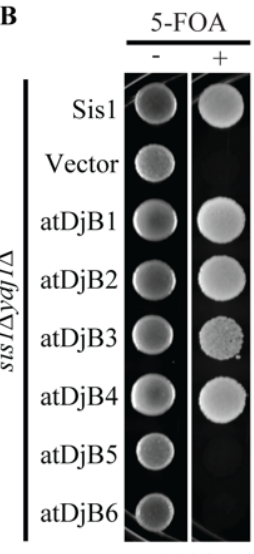

$30^{\circ} \mathrm{C}$

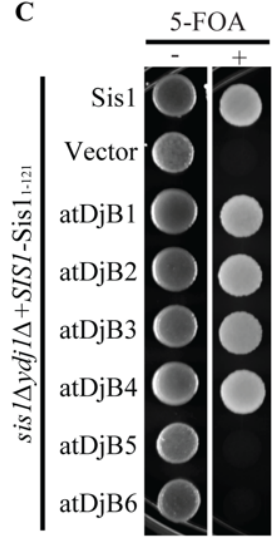

$30^{\circ} \mathrm{C}$

Fig. 9. atDjB1-6 differentially rescue the generalized functions of Ydj1 in $\boldsymbol{S}$. cerevisiae. A. Equal volume of ten-fold serial dilutions of $y d j 1 \Delta$ cells harboring empty pRS414 plasmid (vector) or pRS414 expressing Ydj1, Sis1 or atDjB1-6 were spotted on YPD plates and incubated at $23^{\circ} \mathrm{C}, 30^{\circ} \mathrm{C}$ and $34^{\circ} \mathrm{C}$ for 3 days. B. Equal volume of ten-fold serial dilutions of sis $1 \Delta y d j 1 \Delta$ [URA3-SIS1] harboring empty pRS414 plasmid (vector) or pRS414 expressing Sis1 or atDjB1-6were spotted on media with $(+)$ and without (-) 5-fluoroorotic acid (5-FOA) and incubated at $30^{\circ} \mathrm{C}$ for 4 days. C. Equal volume of ten-fold serial dilutions of sis $1 \Delta y d j 1 \Delta$ [URA3-SIS1 and pRS313-Sis1 $1_{1-121}$ ] harboring empty pRS414 plasmid (vector) and pRS414 expressing Sis1 or atDjB1-6were spotted on media with (+) and without (-) 5fluoroorotic acid (5-FOA) and incubated at $30^{\circ} \mathrm{C}$ for 4 days. 


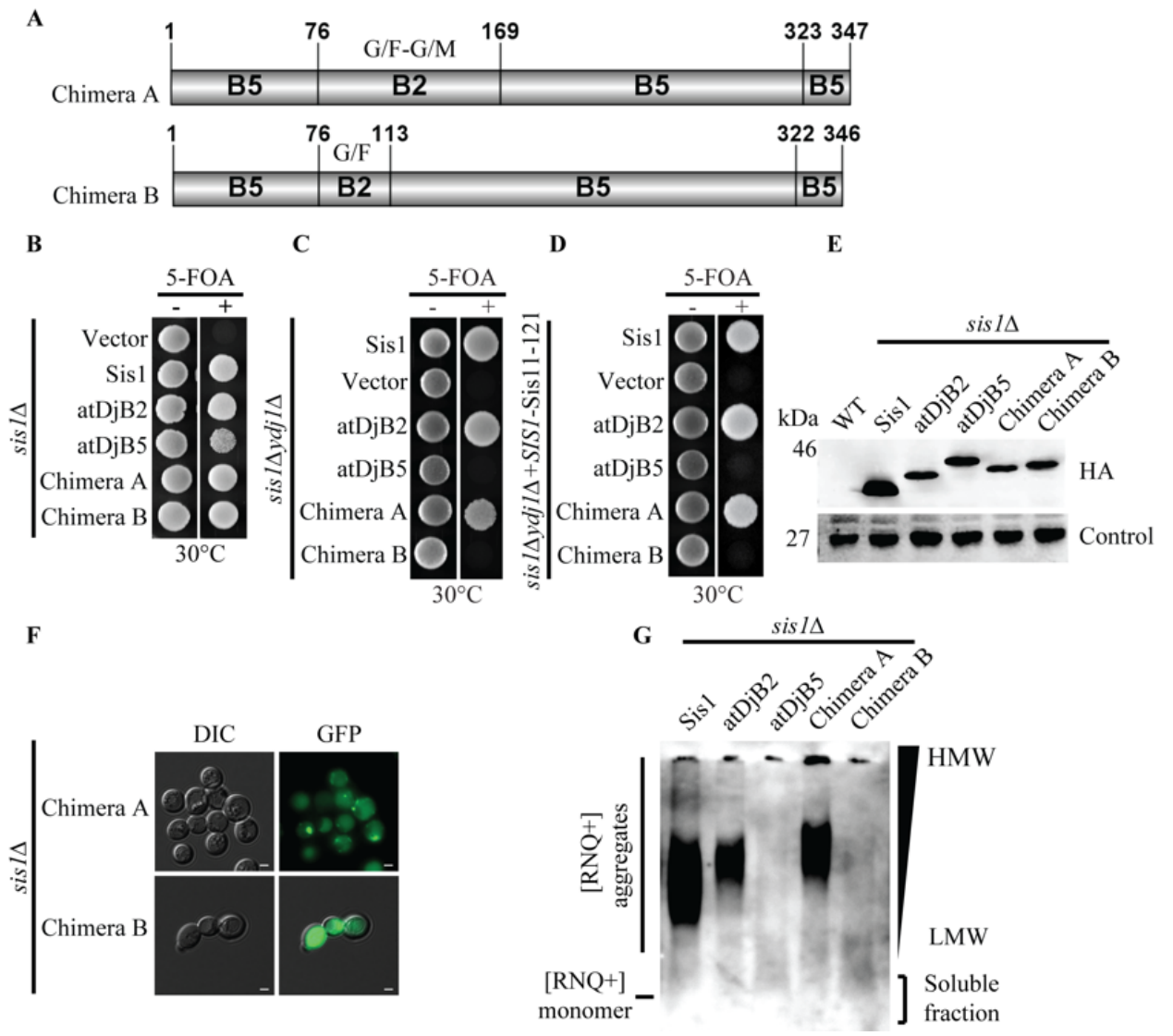

Fig.10. Conserved GF/GM region defines the functional specificity among atDjBs. A. Domain organization of Chimera A and B. Chimera A contains the following amino acids: B5 (1-76):B2 (80173):B5 (172-349). Chimera B contains the following amino acids: B5 (1-76):B2 (80-117):B5 (118349). Please see the MATERIALS AND METHODS for details about the construction of Chimera A and Chimera B. B.Equal volume of ten-fold serial dilutions of sis $1 \Delta$ [URA3-SISI] cells harboring empty pRS414 plasmid (vector) or pRS414 expressing Sis1 or Chimera A/B were spotted on media with $(+)$ or without (-) 5-fluoroorotic acid (5-FOA) and incubated at $30^{\circ} \mathrm{C}$ for 3 days. C. Equal volume of tenfold serial dilutions of sis $1 \Delta y d j 1 \Delta$ [URA3-SIS1] harboring empty pRS414 plasmid (vector) and pRS414 expressing Sis 1 or Chimera A/B were spotted on media with (+) and without (-) 5-fluoroorotic acid (5FOA) and incubated at $30^{\circ} \mathrm{C}$ for 4 days. D. Equal volume of ten-fold serial dilutions of sis $1 \Delta y d j 1 \Delta$ [URA3-SIS1 and pRS313-Sis $1_{1-121}$ ] harboring empty pRS414 plasmid (vector) and pRS414 expressing Sis 1 or Chimera A/B were spotted on media with (+) and without (-) 5-fluoroorotic acid (5-FOA) and incubated at $30^{\circ} \mathrm{C}$ for 4 days. E. Equal amounts of total cell lysate prepared from sis $1 \Delta$ cells harboring plasmids expressing HA-tagged constructs of Sis1 and Chimera A/B were resolved on SDS-PAGE, electroblotted, and probed with anti-HA antibody. Anti-TBP1 antibody was used as loading control. WT cells were included as negative control. F.sis $1 \Delta$ cells [URA3-SISI] bearing $\left[R N Q^{+}\right]$examined in this study was used for subsequent transformation of each shuffled strain by a Rnq1-GFP reporter plasmid (pRS413-TEF-RNQ1-GFP) followed by fluorescence microscopy analysis. Scale bar, $2 \mu \mathrm{m}$. G. Protein lysate prepared from shuffled strain of sis $1 \Delta$ cells harboring constructs of Sis 1 or Chimera $\mathrm{A} / \mathrm{B}$ were resolved on semi-denaturing detergent agarose gel electrophoresis (SDDAGE), electroblotted, and probed with anti-Rnq1 antibody. 


\begin{tabular}{|c|c|c|}
\hline atDjB2 & 1 & 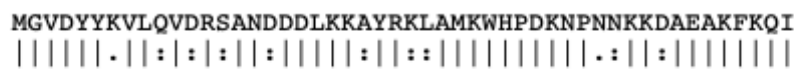 \\
\hline atDjB5 & 1 & MGVDYYNVLKVNRNANEDDLKKSYRRMAMKWHPDKNPTSKKEAEAKFKQI \\
\hline atDjB2 & 51 & 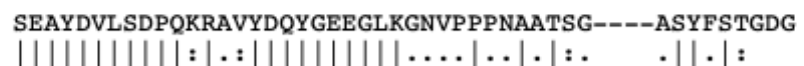 \\
\hline atDjB5 & 51 & SEAYDVLSDPQRRQIYDQYGEEGLKSTDLPTAAETAAHQQQRSYSSS--- \\
\hline atDjB2 & 97 & $\begin{array}{l}\text { SSSFRFNPRSADDIFAEFFGFS-TPFGGG-------GGGTGGQRFASRM } \\
:\end{array}$ \\
\hline atDjB5 & 98 & NSEFRYYPRDAEDIFAEFFGESGDAFGGGSSGRTRGDGGDGGGRRFKS-- \\
\hline atDjB2 & 138 & 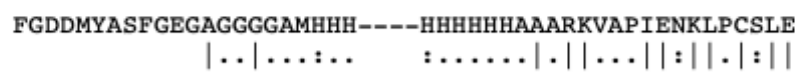 \\
\hline atDjB5 & 146 & ------------AEAGSQANRKTPPTNKKTTPPANRKAPAIESKLACTLE \\
\hline atDjB2 & 184 & $\begin{array}{l}\text { DLYKGTTKKMKISREIVDVSGKAMQVEEILTIGVKPGWKKGTKITFPEKG } \\
:|||| \ldots|||:||| \cdot: \cdot|\ldots||\ldots|:|||\cdot| \cdot||||||||||||||||\end{array}$ \\
\hline atDjB5 & 184 & ELYKGAKKKMRISRVVPDDFGKPKTVQEILKIDIKPGWKKGTKITFPEKG \\
\hline atDjB2 & 234 & 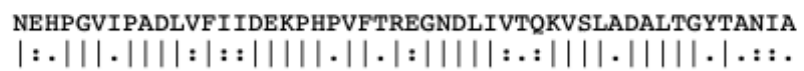 \\
\hline atDjB5 & 234 & NQEPGVTPADLIFVVDEKPHSVFKRDGNDLILEKKVSLIDALTGLTISVT \\
\hline atDjB2 & 284 & 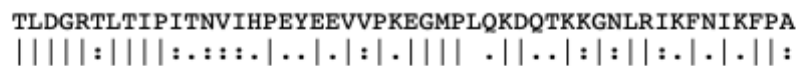 \\
\hline atDjB5 & 284 & TLDGRSLTIPVLDIVKPGQEIVIPNEGMP-TKDPLKRGDLRVTFEILFPS \\
\hline atDjB2 & 334 & $\begin{array}{l}\text { RLTAEQKAGFKKLIG-- } \\
|||:||| \cdots|:::|\end{array}$ \\
\hline atDjB5 & 333 & RLTSEQKNDLKRVLGGS \\
\hline
\end{tabular}

Fig. S8. Sequence alignment of the atDjB2 and atDjB5 proteins. Pairwise alignment of amino acid sequences of the atDjB2 and atDjB5 proteins of $A$. thaliana carried out by an online tool EMBOSS Needle that uses the Needleman-Wunsch alignment algorithm. 
A

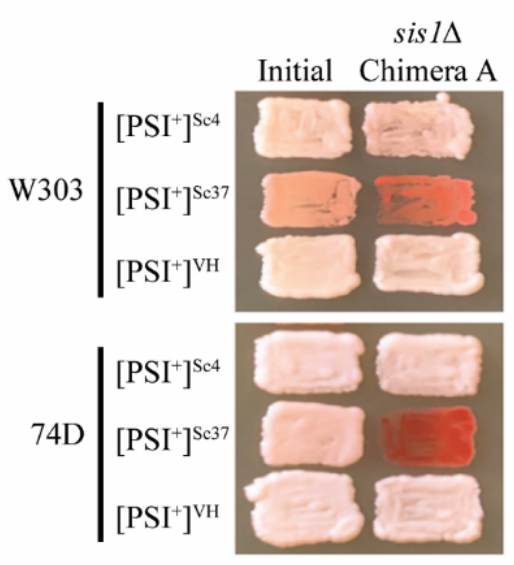

C

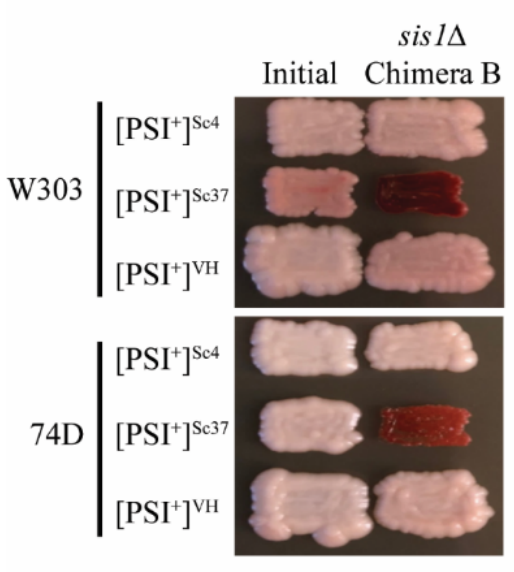

B

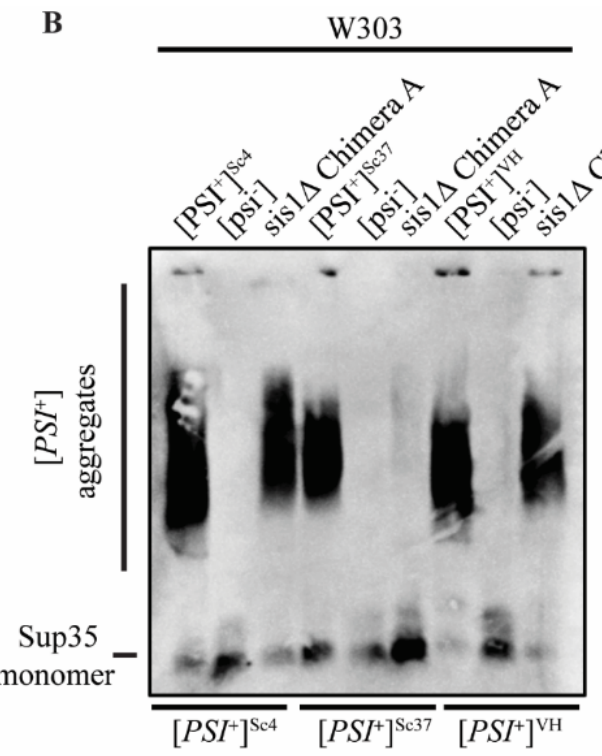

W303
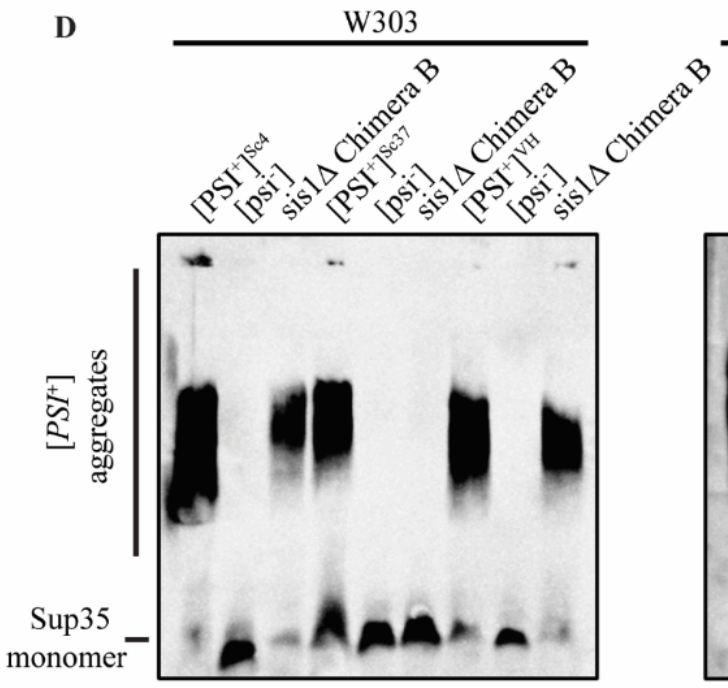

D
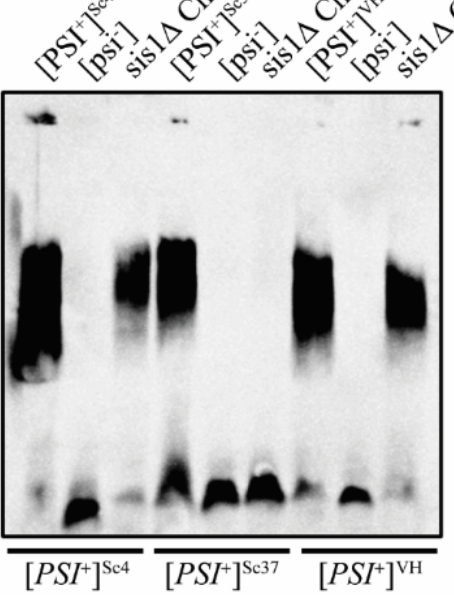

$74 \mathrm{D}$

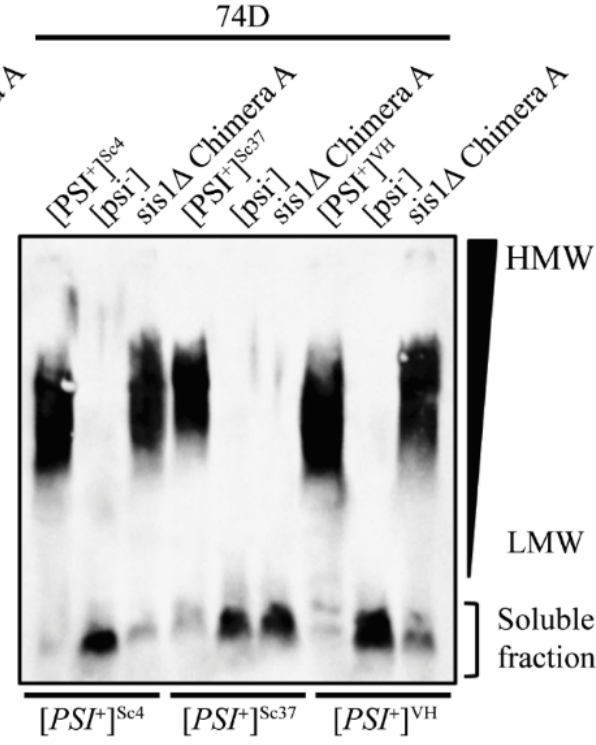

$74 \mathrm{D}$

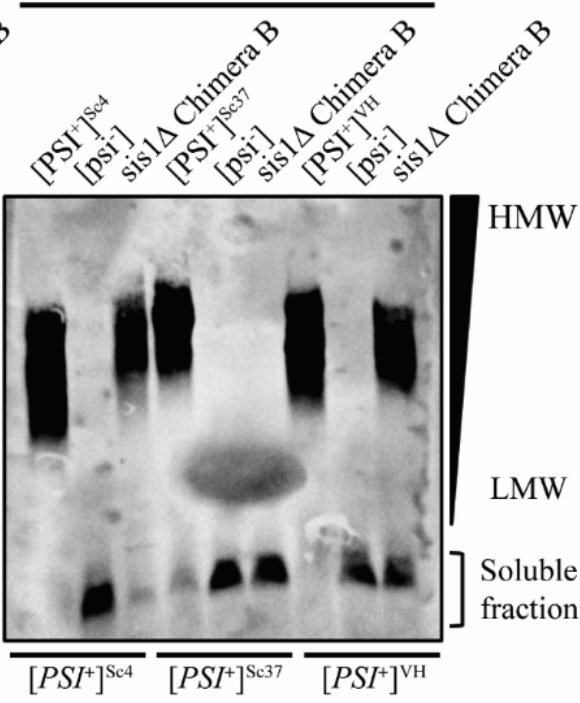

Fig. S9. Chimera A and Chimera $\mathrm{B}\left[\mathrm{PSI}^{+}\right]$prion maintenance abilities are indistinguishable between $W 303$ and $74 \mathrm{D}-694$ yeast genetic backgrounds. $A$ and $B$. $\left[P S I^{+}\right]^{\mathrm{Sc} 4},\left[P S I^{+}\right]^{\mathrm{Sc} 37}$, and $\left[P S I^{+}\right]^{\mathrm{VH}}$ sis $1 \Delta$ [URA3-SIS1] cells from two genetic backgrounds, W303 and74D-694, were transformed with plasmid (pRS414) expressing Chimera A and subjected to plasmid shuffling on 5-fluorooratic acid (5-FOA). Cells from individual transformations were assayed for $\left[\mathrm{PSI}^{+}\right]$maintenance by colony color on YPD media (A). Equal amounts of cell lysate prepared from shuffled strains were resolved by SDDAGE, electroblotted, and probed with anti-Sup35 antibody $(\mathbf{B}) .\left[\mathrm{PSI}^{+}\right]$and GdnHCl-treated $\left[p s i^{-}\right]$ parent cells were included for comparison. $\mathbf{C}$ and D. $\left[P S I^{+}\right]^{\mathrm{Sc} 4},\left[P S I^{+}\right]^{\mathrm{Sc} 37}$, and $\left[P S I^{+}\right]^{\mathrm{VH}}$ sis $1 \Delta[U R A 3-$ SIS1] cells from two genetic backgrounds, W303 and74D-694, were transformed with plasmid (pRS414) expressing Chimera B and subjected to plasmid shuffling on 5-fluorooratic acid (5-FOA). Cells from individual transformations were assayed for $\left[\mathrm{PSI}^{+}\right]$maintenance by colony color on YPD media (C). Equal amounts of cell lysate prepared from shuffled strains were resolved by SDDAGE, electroblotted, and probed with anti-Sup35 antibody $(\mathbf{D}) .\left[\mathrm{PSI}^{+}\right]$and $\mathrm{GdnHCl}$-treated $\left[\mathrm{psi}^{-}\right]$parent cells were included for comparison. 


\section{Tables}

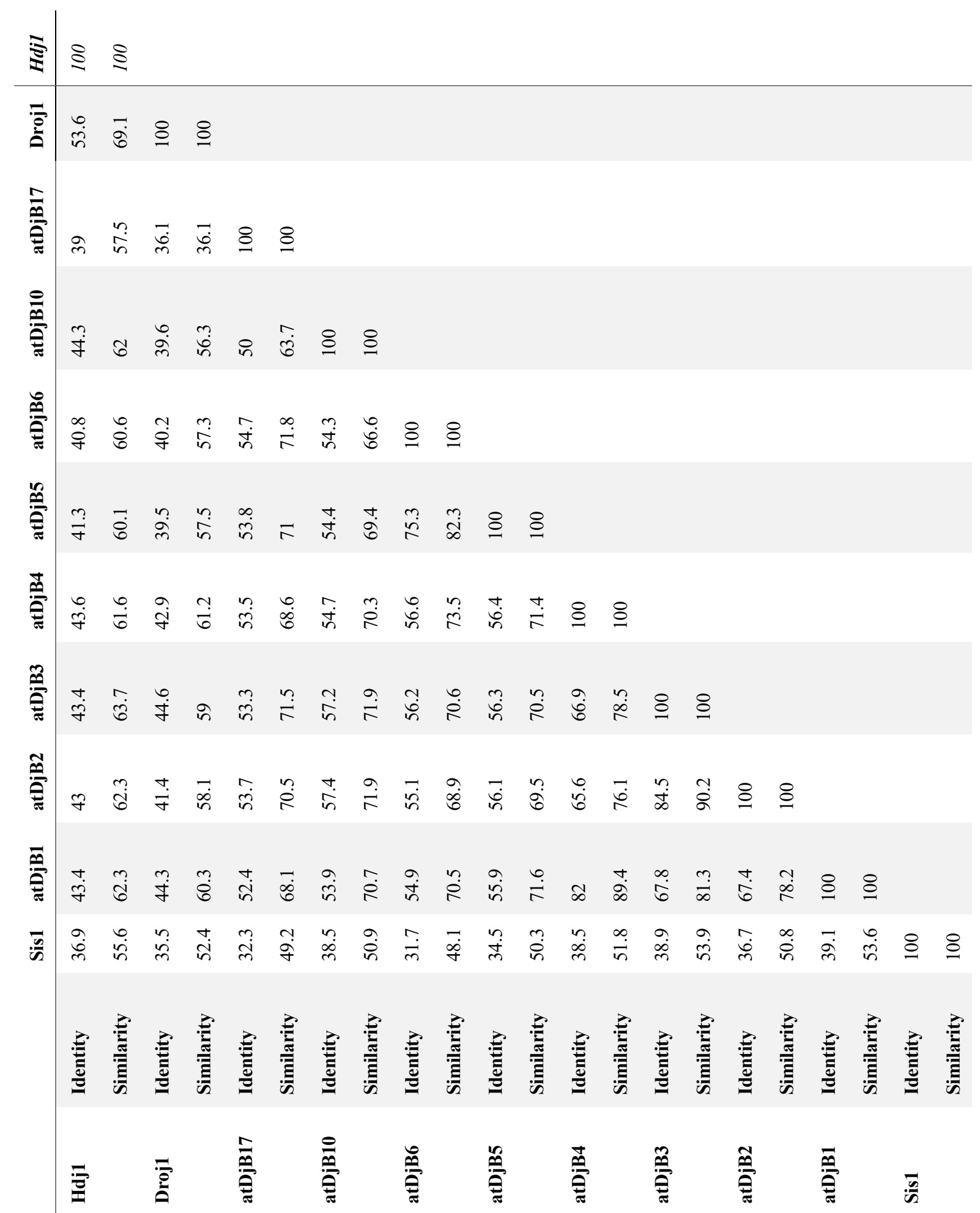

Table 1. Percent amino acid sequence similarity and identity among $A$. thalianaatDjBs, Sis1, Droj1 and Hdj1. Full length protein sequences were used to calculate the similarity and identity with EMBOSS Needle online tool. 
Supporting Table 1. List of Primers used in this work.

\begin{tabular}{|c|c|c|}
\hline \multicolumn{3}{|c|}{ Cloning primers } \\
\hline Primer name & Forward & Reverse \\
\hline Sis 1 & $\begin{array}{l}\text { ATAGGATCCATGGTCAAGGAG } \\
\text { ACAAAACT }\end{array}$ & $\begin{array}{l}\text { ACGCGTCGACTTAAAAATTTTCATC } \\
\text { TATAG }\end{array}$ \\
\hline Sis1-HA & $\begin{array}{l}\text { ATCCACTAGTATGTACCCATA } \\
\text { CGATGTTCCAGATTACGCTGG } \\
\text { ATCCATGGTCAAGGAGACAAA } \\
\text { ACT }\end{array}$ & $\begin{array}{l}\text { ACGCGTCGACTTAAAAATTTTCATC } \\
\text { TATAG }\end{array}$ \\
\hline atDjB1 & $\begin{array}{l}\text { ATAGGATCCATGGGGGTTGAT } \\
\text { TTCTATAAG }\end{array}$ & $\begin{array}{l}\text { ACGGTCGACTCAAGGTGATAACAT } \\
\text { CCGCTTG }\end{array}$ \\
\hline atDjB2 & $\begin{array}{l}\text { ATAGGATCCATGGGAGTTGAT } \\
\text { TATTACAAGGT }\end{array}$ & $\begin{array}{l}\text { ACGCGTCGACTCACCCAATAAGCTT } \\
\text { CTTAAACC }\end{array}$ \\
\hline atDjB3 & $\begin{array}{l}\text { ATAGGATCCATGGGAGTGGAT } \\
\text { TACTACAAAG }\end{array}$ & $\begin{array}{l}\text { ACGCGTCGACTCATCCGAGAAGTTT } \\
\text { CTTCACTC }\end{array}$ \\
\hline atDjB4 & $\begin{array}{l}\text { ATAGGATCCATGGGGGTCGAT } \\
\text { TATTACAAGG }\end{array}$ & $\begin{array}{l}\text { GCTTATCGATCTAGGAAGACGAAA } \\
\text { ACATTCG }\end{array}$ \\
\hline atDjB5 & $\begin{array}{l}\text { ATAGGATCCATGGGGGTGGAT } \\
\text { TACTACAATGTTCTG }\end{array}$ & $\begin{array}{l}\text { ACGCGTCGACTCAGCTTCCACCAAG } \\
\text { AACT }\end{array}$ \\
\hline atDjB6 & $\begin{array}{l}\text { ATAGGATCCATGGGGGTTGAT } \\
\text { TACTACAATGTACTC }\end{array}$ & $\begin{array}{l}\text { ACGCGTCGACTCAGCTACCACCAA } \\
\text { GAACTC }\end{array}$ \\
\hline Chimera A-F1 & $\begin{array}{l}\text { ATAGGATCCATGGGGGTGGAT } \\
\text { TACTACAATGTTCTGAAAGTG }\end{array}$ & $\begin{array}{l}\text { CCACTAGTAGCAGCATTGGGGGAT } \\
\text { TTAAGACCTTCTTCTC }\end{array}$ \\
\hline Chimera A-F2 & $\begin{array}{l}\text { GAGAAGAAGGTCTTAAATCCC } \\
\text { CCAATGCTGCTACTAGTGG }\end{array}$ & $\begin{array}{l}\text { GCCAATTTACTCTCAATAGCAGGAG } \\
\text { CCACTTTCCTAGCTG }\end{array}$ \\
\hline Chimera A-F3 & $\begin{array}{l}\text { CAGCTAGGAAAGTGGCTCCTG } \\
\text { CTATTGAGAGTAAATTGGC }\end{array}$ & $\begin{array}{l}\text { ACGCGTCGACTCAGCTTCCACCAAG } \\
\text { AACTCTCTTG }\end{array}$ \\
\hline Chimera B-F1 & $\begin{array}{l}\text { ATAGGATCCATGGGGGTGGAT } \\
\text { TACTACAATGTTCTGAAAGTG }\end{array}$ & $\begin{array}{l}\text { CCACTAGTAGCAGCATTGGGGGAT } \\
\text { TTAAGACCTTCTTCTC }\end{array}$ \\
\hline Chimera B-F2 & $\begin{array}{l}\text { GAGAAGAAGGTCTTAAATCCC } \\
\text { CCAATGCTGCTACTAGTGG }\end{array}$ & $\begin{array}{l}\text { CCAAAAGCATCACCGGATTCGAAC } \\
\text { CCGAAAAACTCAGCGA }\end{array}$ \\
\hline Chimera B-F3 & $\begin{array}{l}\text { TCGCTGAGTTTTTCGGGTTCGA } \\
\text { ATCCGGTGATGCTTTTGG }\end{array}$ & $\begin{array}{l}\text { ACGCGTCGACTCAGCTTCCACCAAG } \\
\text { AACTCTCTTG }\end{array}$ \\
\hline atDjB1 $1_{157-335}$ & $\begin{array}{l}\text { GTCTGGATCCTCTGAACCTATT } \\
\text { GAAAGAC }\end{array}$ & $\begin{array}{l}\text { GATACTCGAGTCATGATAACATCCG } \\
\text { CTTG }\end{array}$ \\
\hline \multicolumn{3}{|c|}{ Gateway cloning primers } \\
\hline Primer name & Forward & Reverse \\
\hline atDjB1 & $\begin{array}{l}\text { GGGGACAAGTTTGTACAAAAA } \\
\text { AGCAGGCTGGATGGGGGTTGA } \\
\text { TTTCTAT }\end{array}$ & $\begin{array}{l}\text { GGGGACCACTTTGTACAAGAAAGC } \\
\text { TGGGTGAGGTGATAACATCCGCTTG }\end{array}$ \\
\hline atDjB2 & $\begin{array}{l}\text { GGGGACAAGTTTGTACAAAAA } \\
\text { AGCAGGCTGGATGGGAGTTGA } \\
\text { TTATTACAAGGT }\end{array}$ & $\begin{array}{l}\text { GGGGACCACTTTGTACAAGAAAGC } \\
\text { TGGGTGCCCAATAAGCTTCTTAAAC } \\
\text { CCA }\end{array}$ \\
\hline atDjB3 & $\begin{array}{l}\text { GGGGACAAGTTTGTACAAAAA } \\
\text { AGCAGGCTGGATGGGAGTGGA } \\
\text { TTACTACAAAG }\end{array}$ & $\begin{array}{l}\text { GGGGACCACTTTGTACAAGAAAGC } \\
\text { TGGGTGTCCGAGAAGTTTCTTCACT } \\
\text { CCTGT }\end{array}$ \\
\hline
\end{tabular}




\begin{tabular}{|l|l|l|}
\hline atDjB4 & $\begin{array}{l}\text { GGGGACAAGTTTGTACAAAAA } \\
\text { AGCAGGCTGGATGGGGGTCGA } \\
\text { TTATTAC }\end{array}$ & $\begin{array}{l}\text { GGGGACCACTTTGTACAAGAAAGC } \\
\text { TGGGTGGGAAGACGAAAACATTCG } \\
\text { T }\end{array}$ \\
\hline atDjB5 & $\begin{array}{l}\text { GGGGACAAGTTTGTACAAAAA } \\
\text { AGCAGGCTGGATGGGGGTGGA } \\
\text { TTAC }\end{array}$ & $\begin{array}{l}\text { GGGGACCACTTTGTACAAGAAAGC } \\
\text { TGGGTGGCTTCCACCAAGAACTCT }\end{array}$ \\
\hline atDjB6 & $\begin{array}{l}\text { GGGGACAAGTTTGTACAAAAA } \\
\text { AGCAGGCTGGATGGGGGTTGA } \\
\text { TTACTAC }\end{array}$ & $\begin{array}{l}\text { GGGGACCACTTTGTACAAGAAAGC } \\
\text { TGGGTGGCTACCACCAAGAACTCTC }\end{array}$ \\
\hline atHsp101 & $\begin{array}{l}\text { GGGGACAAGTTTGTACAAAAA } \\
\text { AGCAGGCTGGATGAATCCAGA } \\
\text { GAAATTC }\end{array}$ & $\begin{array}{l}\text { GGGGACCACTTTGTACAAGAAAGC } \\
\text { TGGGTGTAATCCTCGATCATTTCC }\end{array}$ \\
\hline \multicolumn{2}{|c|}{ Forward } & \multicolumn{1}{|c|}{ RT primer } \\
\hline Primer name & \multicolumn{2}{|c|}{ Reverse } \\
\hline atDjB1 & CAATTGCCTTGTAGCTTGGA & CCAGGAAGGTTATCTTGTTCC \\
\hline atDjB2 & GTTGCCTTGTAGCCTTGAAGA & TGGAATCACACCTGGATGCT \\
\hline atDjB3 & ATCACGGTGGAGCTAGGAAG & TGGGAACGTGATCTTTGTGC \\
\hline atDjB4 & $\begin{array}{l}\text { GACAACTTCCTTGTAGTTTGGA } \\
\text { AGA }\end{array}$ & CCTTTCTCCGGGAAGGTAAT \\
\hline atDjB5 & CTTGCACATTGGAGGAGCTC & CAGGAGTGACACCAGGTTCT \\
\hline atDjB6 & AAGATTCCCGCGTTGTTCC & AGATCTGCGGGAGTAACACC \\
\hline atDjB10 & CCTCCACCGGTTGAGAGTAA & TGCTCATTTCCTTTGTCTGGA \\
\hline atDjB17 & TGCCTGTGAGTTTGGAGGAT & TGATTCCAGGCTCTTCATTGC \\
\hline
\end{tabular}

